\title{
The value of energy storage in decarbonizing the electricity sector
}

Fernando J. de Sisternes $^{1,2^{*}}$, Jesse D. Jenkins ${ }^{1,2^{*}}$, Audun Botterud ${ }^{1,2}$

\footnotetext{
${ }^{1}$ Energy Systems Division, Argonne National Laboratory, 9700 S. Cass Avenue, Building 362, Argonne, IL 60439-4844 USA.

${ }^{2}$ MIT Energy Initiative, Massachusetts Institute of Technology, 77 Massachusetts Avenue, E19-307, Cambridge, MA 02139-4307 USA.

*Email: ferds@anl.gov; jessedj@mit.edu
} 


\begin{abstract}
Electrical energy storage could play an important role in decarbonizing the electricity sector by offering a new, carbon-free source of operational flexibility, improving the utilization of generation assets, and facilitating the integration of variable renewable energy sources. Yet, the future cost of energy storage technologies is uncertain, and the value that they can bring to the system depends on multiple factors. Moreover, the marginal value of storage diminishes as more energy storage capacity is deployed. To explore the potential value of energy storage in deep decarbonization of the electricity sector, we assess the impact of increasing levels of energy storage capacity on both power system operations and investments in generation capacity using a generation capacity expansion model with detailed unit commitment constraints. In a case study of a system with load and renewable resource characteristics from the U.S. state of Texas, we find that energy storage delivers value by increasing the cost-effective penetration of renewable energy, reducing total investments in nuclear power and gas-fired peaking units, and improving the utilization of all installed capacity. However, we find that the value delivered by energy storage with a 2-hour storage capacity only exceeds current technology costs under strict emissions limits, implying that substantial cost reductions in battery storage are needed to justify large-scale deployment. In contrast, storage resources with a 10-hour storage capacity deliver value consistent with the current cost of pumped hydroelectric storage. In general, while energy storage appears essential to enable decarbonization strategies dependent on very high shares of wind and solar energy, storage is not a requisite if a diverse mix of flexible, low-carbon power sources is employed, including flexible nuclear power.
\end{abstract}

Keywords: energy storage, climate change, decarbonization, renewable energy integration, capacity planning 


\section{Introduction}

The electric power sector must play a central role in any effort to mitigate the worst impacts of climate change. Most climate stabilization scenarios envision the global power sector emitting very low or zero carbon dioxide $\left(\mathrm{CO}_{2}\right)$ by 2050 while also expanding to electrify and decarbonize portions of the industry and transportation sectors [1] [2]. Electrical energy storage could play an important role in the deep decarbonization of the power sector by offering a new, carbon-free source of operational flexibility in the power system, improving the utilization of generation assets, and facilitating the integration of variable renewable energy sources (i.e., wind and solar power) [3] [4]. Most of the value of energy storage is accrued from its ability to arbitrage wholesale prices during peak and non-peak hours, thereby leveling out the system load [5] [6] [7] [8], but also from providing a carbon-free source of operating reserves and flexibility [9] [10] [11] [12] that might potentially defer investments in other more expensive generation assets [13] [14].

To date, many studies have examined the short-run impact of energy storage on electric power system operations and economics [5] [6] [7] [8] [9] [14] [15] [16] [17] [18]. Some of these studies have focused on the role of energy storage for integrating large amounts of variable renewable energy generation in power system operations [9] [15] [16], and others have assessed the impact of storage operation on carbon emissions in conventional power systems [17] [18]. Studies assessing the short-run value of energy storage in different electricity markets typically employ price-taker arbitrage models (i.e., models that maximize the profits of the storage unit assuming that storage does not impact electricity prices) [5] [6] [7] [8] [14], while others calculate the short-run price equilibrium minimizing the system operating costs but ignoring long-run capacity expansion decisions [11] [12].

The long-run impact of energy storage on renewable energy utilization is explored in [19]. However, this study does not account for economic considerations and maximizes a multiobjective function composed of renewable penetration minus storage and backup requirements, 
instead of using the standard criterion of maximizing social welfare — or, equivalently, minimizing total generation costs. Conversely, the long-run economic impact of storage is analyzed in [13] and [20] based on cost minimization, but these studies do not include binding $\mathrm{CO}_{2}$ emissions limits for the electricity sector. Other studies that consider the long-run market dynamics under stringent $\mathrm{CO}_{2}$ emissions limits [21] [22] do not consider detailed unitcommitment constraints in the operation of the plants, underestimating the flexibility value energy storage technologies bring to power systems.

In contrast to the existing literature discussed above, this paper focuses explicitly on the total generation-system value of energy storage. ${ }^{1}$ We explore in detail the impact of energy storage on short-run power systems operations - accounting for detailed unit-commitment decisions, the contribution of storage to system flexibility and operating reserves, and the resulting influence on wholesale electricity prices - as well as the impact of energy storage on long-run power plant investment decisions, all in the context of stringent $\mathrm{CO}_{2}$ emissions reduction goals. This work therefore adds to the existing literature by providing a more complete assessment of the full economic value of energy storage through jointly capturing both the short- and long-run interaction between storage, renewable energy, and other zero-carbon electricity sources and their relative contributions to meet demands for energy and operating reserves along with emissions reduction objectives. The novel analytical framework used in this work can be applied to more accurately value energy storage in indicative planning [23] for future low-carbon power systems, where the $\mathrm{CO}_{2}$ emissions and flexibility attributes of the different generation technologies play a critical role in determining the minimum cost generation fleet that is operationally feasible and complies with a given carbon emissions limit.

\footnotetext{
${ }^{1}$ By generation-system value we refer to the full value of generation, including capital and operating costs for meeting energy and ancillary services needs, but without accounting for transmission or distribution costs, which are very much contingent on the particular power system analyzed.
} 
In our analysis we made extensions to the Investment Model for Renewable Electricity Systems (IMRES) [24], an advanced generation capacity expansion model that considers unit commitment constraints for individual power plants, system-wide reliability requirements, and individual power plant investment decisions. The model selects the cost-minimizing set of investments in electricity generation capacity to reliably meet the electricity demand in a future year, subject to a $\mathrm{CO}_{2}$ emissions limit. ${ }^{2}$ We model a power system with electricity demand and wind and solar resource data from the Electricity Reliability Corporation of Texas (ERCOT) grid. To explore the impacts of storage on the long-run portfolio of power generation capacity, we increase demand consistent with 2035 projections in Texas and employ the model in a "greenfield" configuration - i.e., selecting the entire generation mix from scratch. Eligible technologies include pulverized coal, combined cycle gas turbines (CCGTs), open cycle gas turbines (OCGTs), wind turbines, solar photovoltaics, and nuclear power. The nuclear power plants are modeled as capable of flexible operation consistent with reactors in France, Germany and other locations [25] [26] [27] as well as modern reactor capabilities [28] [29]. We model this experimental power system assuming no transmission network constraints and imposing both increasing levels of energy storage capacity and increasingly stringent limits on the average $\mathrm{CO}_{2}$ emissions rate of the electricity system. Specifically, we model 0-30 gigawatts (GW) of energy storage, representing approximately $0-30 \%$ of the system's peak demand, and emissions limits of 200-50 metric tons of $\mathrm{CO}_{2}$ per gigawatt-hour $\left(\mathrm{tCO}_{2} / \mathrm{GWh}\right)$, approximately $60-90 \%$ below prevailing 2013 emissions rates in the United States (514 $\mathrm{tCO}_{2} / \mathrm{GWh}$ ) [30] or the European Union $\left(567 \mathrm{tCO}_{2} / \mathrm{GWh}\right)[31]$.

The contributions of this paper can be summarized as follows: 1) We present a comprehensive analytical framework for assessment of the full generation-system value of energy storage technologies in long-run economic equilibrium, accounting for detailed, short-term

\footnotetext{
2 The $\mathrm{CO}_{2}$ emissions limit applies only to emissions from power plants during operations and does not include emissions associated with construction, decommissioning or other lifecycle related emissions.
} 
operational constraints as well as $\mathrm{CO}_{2}$ emissions goals. The novel analytical framework allows for a more accurate assessment of energy storage benefits compared to what is found in the existing literature. 2) We conduct a detailed case study of the role of energy storage in a future power system based on ERCOT data and with increasingly stringent $\mathrm{CO}_{2}$ emissions targets. We find that the value of energy storage increases with tighter emissions targets. At the same time, the marginal value of storage declines significantly as storage capacity increases and substantial cost reductions are likely needed to economically justify large-scale deployment of most storage technologies.

The paper is organized as follows: Section 2 introduces the methodological approach and the experimental design used in the analysis. Section 3 presents the economic and technical results under three different hypothetical conditions, each of which is exposed to increasingly stringent emissions limits: a power system without energy storage and a diverse range of generation resources, a power system with energy storage and the same generation resources, and a power system with storage that relies exclusively on renewable energy technologies to reduce carbon emissions. Section 4 and Section 5 present respectively the discussion and the conclusions derived from the analysis.

\section{Methods}

\subsection{Demand, renewables and generation technology cost data sets}

This study models an experimental electricity system with electricity demand and wind and solar resource data from the Electricity Reliability Corporation of Texas (ERCOT) grid. The selection of a 'Texas-like' test system was motivated by the relative lack of hydroelectric resources in Texas and weak interconnection with other neighboring power systems of the ERCOT interconnection, which allows a clear interpretation of the results. To project electricity demand in ERCOT in 2035, we increased historical 2014 hourly electricity demand for the 
ERCOT grid at an annual growth rate of 1.86\% [32], resulting in a system peak load of $97.1 \mathrm{GW}$. Hourly wind resource availability was also obtained from 2014 ERCOT historical data, with an average wind availability of $35.7 \%$. Hourly solar photovoltaic availability was estimated by aggregating data from NREL's PV Watts Model [33] for seven geographically diversified locations in Texas, assuming single-axis tracking systems located in Mineral Wells, Lubbock, Midland, and Marfa and rooftop panels in San Antonio, Austin, and Houston. The resulting average availability of solar photovoltaic was found to be $19.9 \%$.

Other generation technologies considered in the study are dual-unit nuclear pressurized water reactors, dual-unit advanced pulverized coal steam generators, combined-cycle gas turbines (CCGTs), and advanced open-cycle gas turbines (OCGTs). The capital cost of each generation technology was collected from the U.S. Energy Information Administration's Annual Energy Outlook 2014 [32] and the U.S. Department of Energy "Wind Vision" [34] and "SunShot Vision" Reports [35]. Overnight capital costs were annualized using a 10\% discount rate and 30 and 40 years of expected life for renewable and thermal technologies respectively. A summary of the cost parameters for all generating technologies in the study is provided in Table A.1.

\subsection{Experimental design}

The experiments conducted in this study determine the optimal portfolio of thermal and renewable generation capacity necessary to supply the expected hourly electricity demand in 2035 at minimum cost for different exogenously-specified levels of installed energy storage capacity, while accounting for the chronological variability of demand and renewable resources, the system requirements for operating reserves, as well as the operational limits of the installed generating units. With the exception of a reference baseline scenario, each of the analyzed scenarios is subject to a mass-based $\mathrm{CO}_{2}$ limit, representing future possible decarbonization targets. This $\mathrm{CO}_{2}$ limit is implemented as a cap on the total amount of $\mathrm{CO}_{2}$ emissions produced by electricity generation on a yearly basis. For easier comparison with the emissions produced in 
other power systems, we normalize the mass-based limit by the total energy generated and present the emissions limit in the plots as an emissions rate expressed as tons of $\mathrm{CO}_{2}$ emissions per GWh generated.

The experimental setting consists of 35 cases resulting from the possible combinations of seven scenarios of installed energy storage capacity and five scenarios of $\mathrm{CO}_{2}$ emissions limits. Energy storage scenarios range from $0-30 \mathrm{GW}$ of installed capacity (in $10 \mathrm{GW}$ increments) and include two generic energy storage technologies, each of which is represented by a different energy to power ratio: 10:1 (or 10 hours of energy storage at maximum hourly discharge) and 2:1 (or 2 hours of storage). There is a wide range of energy storage technologies commercially available and in development, each with different configurations of power and energy capacities, round-trip efficiencies, cycle life, and other operating parameters [36] [37] [38]. We selected these two generic storage technologies to enable evaluation of the value of different durations of storage capacity. The 2-hour generic storage technology can be considered broadly consistent with commercially available Lithium-ion (Li-ion) battery systems, which are typically installed with energy to power ratios between $0.25: 1$ to $5: 1$ [36]. The 10-hour storage technology is broadly consistent with pumped hydroelectric storage systems, which typically were designed for a daily operating cycle with power ratios ranging from 8:1 to 16:1 [36], although there are examples of pumped storage hydro facilities with more than 20 hours of operating storage as well as storage duration of as little as four hours [38]. To facilitate comparison and evaluation of the value of shorter or longer-duration storage capabilities, both generic technologies are assumed to have a round-trip efficiency of $80 \%$. This is a mid-range value for both pumped-hydro electric storage systems, which have round-trip efficiencies ranging from 70-85\% efficiency [36] [38] and Li-ion systems, which typically range from 73-90\% (including AC/DC and DC/AC power conversion losses) [36]. While these two generic technologies allow for broad comparison of relatively short and long-duration storage resources, care should be taken in using the results 
herein to derive the value of specific storage technologies or installations which may have different characteristics, such as different round-trip efficiency or storage duration.

$\mathrm{CO}_{2}$ emissions limits span a range between $200 \mathrm{t} / \mathrm{GWh}$ and $50 \mathrm{t} / \mathrm{GWh}$ in 50 ton increments, as well as a baseline reference scenario with unconstrained emissions. Note that these limits represent substantial reductions in $\mathrm{CO}_{2}$ emissions relative to current emissions rates in Texas, which stand at approximately $550 \mathrm{t} / \mathrm{GWh}$. Emissions limit scenarios thus correspond to roughly 63-91 percent declines relative to current emissions rates.

In addition to these core scenarios, we also re-analyzed the $100 \mathrm{t} / \mathrm{GWh}$ emissions limit under each of the seven storage scenarios after excluding nuclear power as an eligible generation technology. These scenarios explore the ability of variable renewable energy resources (wind and solar) to meet stringent emissions limits without additional zero-carbon generation resources and the value of storage in such cases.

\subsection{Generation Capacity Expansion Model}

This study employs the generation capacity expansion model IMRES [39] to determine simultaneously the optimal greenfield level of investment in generation capacity-i.e., assuming that there is no existing generating capacity — in each of the cases studied and the optimal operation of these generation investments. IMRES is implemented as a mixed-integer linear programming model using the commercial optimization solver CPLEX. The model selects the combination of available thermal power plants and renewable generation that can supply electricity demand at minimum cost, while complying with operational reliability constraints and the $\mathrm{CO}_{2}$ emission limit imposed on the system. The optimization is done over four representative weeks and the operational results and associated costs are scaled up to approximate annual values.

Analogously to classic static generation capacity expansion models [40], the goal of IMRES is to minimize the total generation cost in the system over one year. These costs can be divided 
into fixed costs (which include the annuity corresponding to the amortization of the capital cost at a $10 \%$ weighted average cost of capital and fixed operation and maintenance cost), variable costs (which include fuel consumption and variable operation and maintenance costs), startup costs for thermal generators (which include the fuel cost of starting up the turbine and the degradation of the turbine from starting up and shutting down), and the cost of non-served energy. The objective function in IMRES is subject to a set of constraints that reflect the operational limits of the different generators in the system (i.e., minimum up and down time, ramping limits, and minimum stable output of the generators). The values of the technical parameters used are included in Table A.2.

Moreover, IMRES requires the resulting generation mix to provide an amount of operating reserves for the system, i.e., available capacity that can be used at any time to balance the system under uncertain events such as the loss of a generator, or forecasting errors in demand, wind or solar generation. The operating reserve requirements for the system are based on the largest single generator in the system, the electricity demand in each hour, and the wind and solar energy generation in each hour. Note that the reserve requirements are determined endogenously in the model and increase with the level of installed wind and solar capacity. Details for the formulation of these constraints can be found in [39]. Combining a capacity expansion formulation with detailed operational constraints and operating reserve requirements enables our study to reflect the impact of the variability and uncertainty of renewable resources on the operation of thermal units, operating reserve requirements, and on capacity expansion decisions, and ultimately the value of energy storage in decarbonizing the electricity sector. These aspects are critical in the analysis of low carbon emissions power systems [13] [24].

In these experiments, we exogenously specify the capacity of energy storage, and then IMRES optimally determines the operation of storage capacity and accounts for the interaction between storage and other operating and capacity expansion decisions. IMRES treats this storage capacity as a single energy reservoir that can store energy within the power and energy limits 
specified for each of the analyzed scenarios. Energy storage is also exposed to a round-trip efficiency factor $(80 \%)$ that reflects the energy losses in the process. Note that since the energy storage capacity in each experiment is an exogenous input, the investment cost of energy storage is not reflected in the objective function of IMRES, which only reflects total generation costs. We however add the cost of storage to the cost of generation in an additional metric representing the total 'system cost' of supplying electricity. Later in the paper (in section 3.5) we take a different perspective and present cost-benefit results of deploying increasing levels of energy storage. These results focus on the value provided by energy storage to the generation system-measured as reduction in generation costs - and compare this to current and future predicted costs for Li-ion and pumped-storage hydro technologies.

\subsection{Time-domain representation}

The variability and uncertainty of renewable resources require generation expansion models that use as input demand and renewable resource data with at least hourly time resolution in order to guarantee the technical feasibility of the solution. However, accounting for the hourly resolution of demand and renewable resources over a time span of one year increases dramatically the dimensionality of the capacity expansion problem. Employing a mixed-integer model to capture detailed investment, unit commitment, and operational constraints further renders the problem computationally intractable for realistic size power systems when using stateof-the-art commercial solvers like CPLEX.

This analysis therefore applies a dimensionality reduction technique based on selecting a set of representative weeks that simultaneously reflect the annual variability of demand, the wind resource, the solar resource and the correlation between them. Choosing contiguous weeks instead of days, load blocks, or other time intervals ensures that the intra-week variability of wind and solar resources, potentially including multiple consecutive days with low or high resource availability, is reflected in the data used by the model. Using selected weeks to represent a full 
year is a common approach in generation expansion planning with renewable resources-e.g., [41] and [42]. The robust week selection process used in this analysis extends the method described in [43], selecting the weeks that most closely represent the full annual net load duration curve (NLDC) as well as the inter-temporal variability of the net load. The error of approximating the NLDC is captured by an 'energy' metric that reflects the root-mean-square error of the difference between the real NLDC and the approximation. The inter-temporal variability of the net load is captured through a 'cycled power' metric that quantifies the height of all the peaks in the net load time series, which is taken as a proxy to the power that must be ramped-up or down throughout the year. Such ramping events are the key driver of generator startup decisions and system flexibility requirements — e.g., ramp rates of committed units. To allow for endogenous determination of renewable energy capacity decisions, we applied a robust selection technique in this study, such that the weeks selected are the ones that minimize the maximum error across the 'energy error' and 'cycled power error' metrics and across a range of potential renewable expansion levels. As Fig. 1 illustrates with the two most extreme examples in terms of renewable capacity deployed, this feature ensures the approximate NLDC closely matches the full annual net load duration curve under any resulting renewable energy capacity ultimately selected by the model. In Fig. 1, the NLDC is determined by the original time series for load and the amount of renewable generation capacity, which in turn is a function of the carbon constraint. The fourweek approximation is determined by the same renewable capacity as the original NLDC, but using only the set of four representative weeks selected. Fig. 2 presents the variability of load and wind and solar resources for the four weeks selected by this algorithm. Load and solar generation both have a distinct daily cycle, whereas the wind generation follows a more random pattern. 


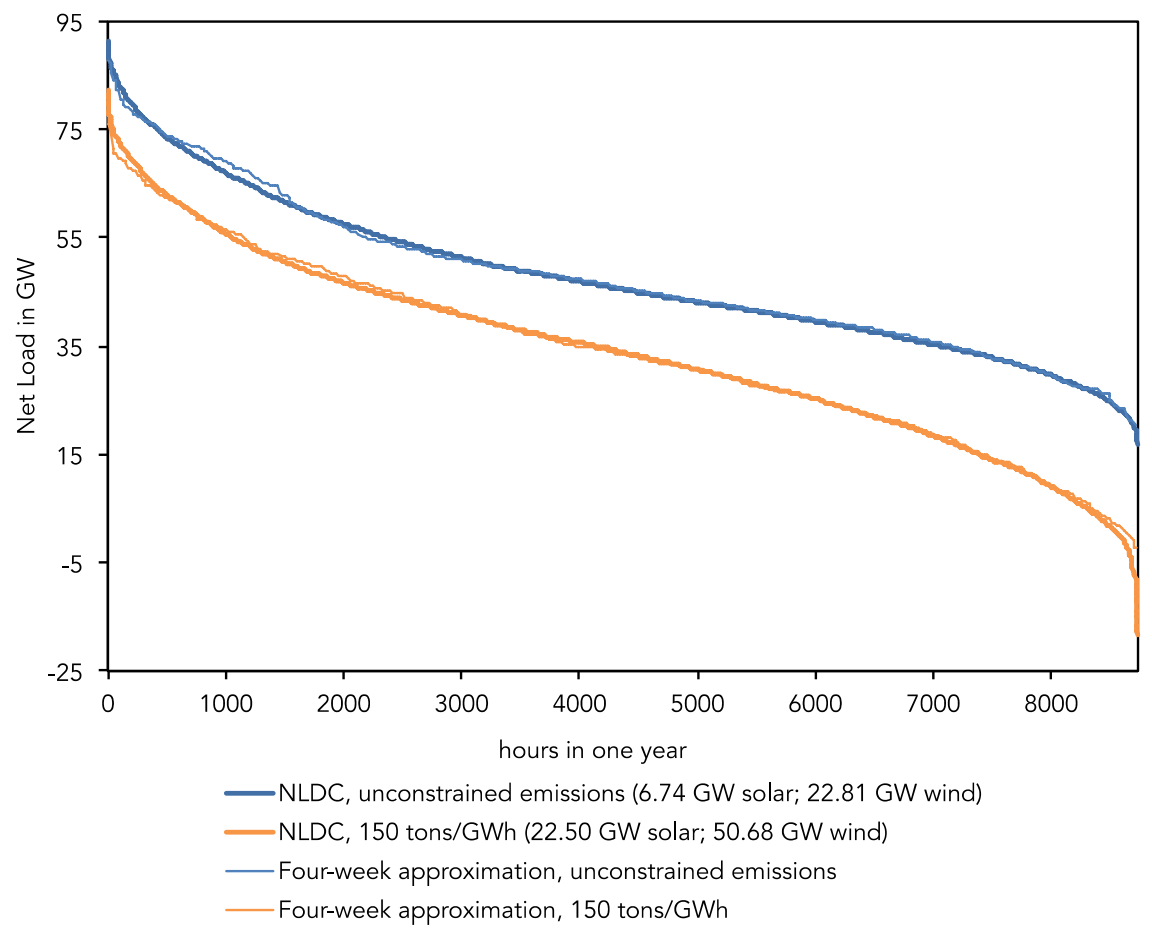

Figure 1 | Four-week approximation and full annual net load duration curve under renewable capacity levels corresponding to lowest and highest renewable investment levels across all "no storage" cases. The two four-week approximations represented are built using the same representative weeks (weeks \#12, \#19, \#27 and \#37). 1-COLUMN FITTING IMAGE

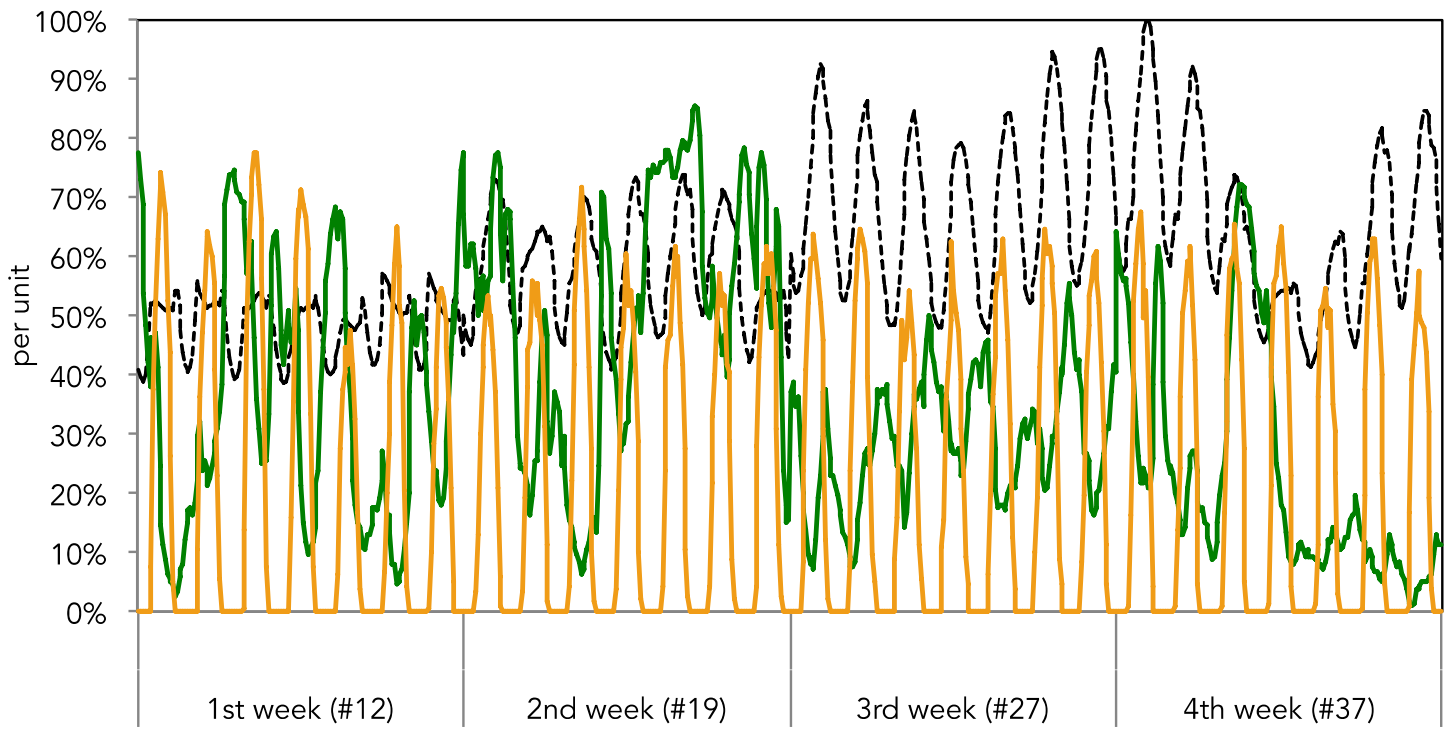

672 hours in the 4 weeks modeled

-----Demand in per unit of peak demand —Wind capacity factor — Solar capacity factor

Figure 2 | Hourly time series of electricity demand and wind and solar resource quality for the four weeks selected by the week selection algorithm and modeled in this study (weeks \#12, \#19, \#27 and \#37). 1 or 2COLUMN FITTING IMAGE AS NEEDED 


\section{Results}

\subsection{Reducing the carbon footprint of electricity without energy storage}

Fig. 3 reports the optimal portfolio of electricity generation under the increasingly stringent emissions limits as well as the average generation costs in the absence of energy storage. Average generation cost $(A G C)$ is defined as the quotient between the total annual generation costs $(T G C)$ and the total annual load:

$$
A G C=\frac{T G C}{\Theta \cdot \sum_{h=1}^{H} D_{h}}, \quad[\mathrm{USD} / \mathrm{MWh}]
$$

where $h$ is the index for the hours in the four weeks selected; $H$ is the total number of hours considered in the simulation ( $H=672$ with a four-week approximation); $\Theta=8,760 / H$ is the weighing factor used to scale up the operating cost of the four-weeks modeled and make it equivalent to full-year operating cost; and $D_{h}$ is the total electricity demand during hour $h$ in MWh.

$T G C$ is defined as the sum of generation investment annual costs, fixed and variable O\&M, fuel costs, start-up costs and the cost of non-served energy divided by the total annual load:

$$
T G C=\sum_{i=1}^{N}\left(1,000 \cdot C_{i}^{F I X} \cdot P_{i}^{M A X}+\Theta \cdot \sum_{h=1}^{H} C_{i}^{V A R} \cdot x_{i h}\right)+\Theta \cdot V O L L \cdot \sum_{h=1}^{H} n_{h} \quad[\mathrm{USD}],(2)
$$

where $i$ is the index for the plants installed in the system; $N$ is the total number of plants installed in the system; $C_{i}^{F I X}$ is the annualized fixed cost of plant $i$ in $\mathrm{USD} / \mathrm{kW}-\mathrm{yr} ; P_{i}^{M A X}$ is the maximum power output of plant $i$ in MW; $C_{i}^{V A R}$ is the variable cost of plant $i$ in USD/MWh; $x_{i h}$ is the energy output of plant $i$ during hour $h$ in MWh; VOLL is the value of lost load in USD/MWh; and $n_{h}$ is the amount of non-served energy during hour $h$ in MWh.

Energy contribution of an individual technology $t \in T\left(E C_{t}\right)$ is defined as the average contribution of generating units of technology $t$ to supplying the total electricity demand over the total number of hours considered in the simulation:

$$
E C_{t}=100 \cdot \frac{\sum_{h=1}^{H} \sum_{i \in t} x_{i h}}{\sum_{h=1}^{H} D_{h}} \quad \forall t \in T \quad[\%]
$$


where $T$ is the set of all available technologies in the system: $T=\{$ nuclear, coal, $C C G T, O C G T$, wind, solar $\}$.

Total generation costs rise $9 \%$ under a $100 \mathrm{tCO}_{2} / \mathrm{GWh}$ emissions rate limit and $15 \%$ under a $50 \mathrm{tCO}_{2} / \mathrm{GWh}$ limit, compared to the reference scenario with no emissions limit. These results are context-specific, and several factors contribute to this relatively modest increase. First, we assume solar, wind, and nuclear each achieve cost reduction targets outlined by industry and the U.S. Department of Energy [34] [35], as summarized in Table A1. Assumed capital costs correspond to a roughly $36 \%$ decline in cost per kilowatt installed for solar and a $25 \%$ decline for wind relative to costs prevailing in the U.S. in 2014 [44] [45] and an 8\% decline in overnight capital costs for nuclear relative to the estimated cost of Vogtle Units 3 and 4 currently under construction in Georgia [46]. Second, Texas possesses relatively abundant renewable energy resources (i.e., historical average availability for wind and solar in 2014 is $35.7 \%$ and $19.9 \%$ respectively) [47]. The total generation costs would increase with higher technology costs and in locations with poorer renewable resources (and vice versa). At the same time, we assume relatively modest natural gas prices consistent with current North American market forecasts [32]. If higher gas prices prevail, the incremental cost of complying with emissions limits would be smaller because the fuel savings generated when low-carbon resources displace gas-fueled plants would be more valuable. Finally, by employing a greenfield capacity mix, we assume that all generation assets must be built from scratch, regardless of the emissions constraint level. Actual costs of compliance with emissions reduction limits could be more costly if existing generation assets must be retired before the end of their useful life, while costs could be lower if existing low-carbon assets can be utilized to meet emissions limits. 


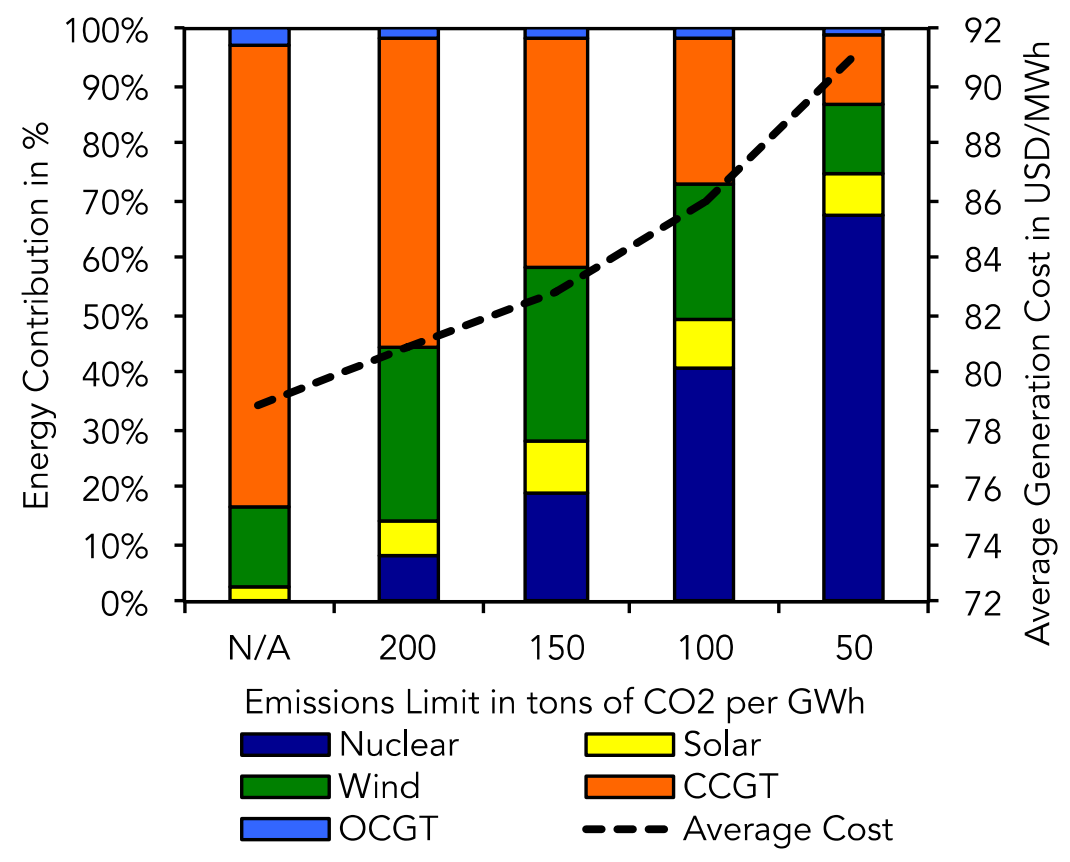

Figure 3 Energy contribution and average cost of electricity generation under various carbon emissions limits, no storage cases. 1-COLUMN FITTING IMAGE

As Fig. 3 illustrates, in the absence of energy storage, wind and solar power reach a maximum penetration level under the 200 and $150 \mathrm{tCO}_{2} / \mathrm{GWh}$ limits, respectively, but each resource's contribution to the low-carbon power mix actually declines as emissions limits tighten further. Wind's contribution to annual energy supplies peaks at $30.3 \%$ and $30.0 \%$ under the 200 and $150 \mathrm{tCO} / \mathrm{GWh}$ emissions limit cases, respectively, and falls to $23.4 \%$ and $12.2 \%$ under the 100 and $50 \mathrm{tCO} 2 / \mathrm{GWh}$ cases. Solar likewise reaches a high of $9.3 \%$ under the $150 \mathrm{tCO} 2 / \mathrm{GWh}$ case and declines to $8.9 \%$ and $7.0 \%$ under the tighter 100 and $50 \mathrm{tCO} / \mathrm{GWh}$ limits. While wind and solar energy are assumed to have lower total cost per unit of electricity delivered than nuclear given the cost and resource quality assumptions used in this study, ${ }^{3}$ the marginal value of these variable renewable resources declines at higher penetrations due to four factors. First, as wind and solar deployment increase, the energy they generate displaces plants with progressively lower

${ }^{3}$ At a capacity factor of $35.7 \%$ without curtailment, wind has a levelized cost of energy (LCOE) of USD 60.31/MWh. With a capacity factor of $19.9 \%$ without curtailment, solar has an LCOE of USD 85.47. And with an annual capacity factor ranging from $91-99 \%$ in the model results for nuclear across cases, nuclear has an LCOE of USD 90.14-96.93. 
variable costs, delivering less value to the system [48]. Second, due to their resource variability, wind and solar contribute only modestly to meeting the peak electricity demand, and their marginal contribution declines as they increase market share [49] [50] [51]. Third, wind and solar curtailment rises at higher penetration levels, reducing the effective capacity factor of these resources [52]. Finally, more wind and solar increases demand for operating reserves, i.e. flexible standby capacity needed to respond to variability and uncertainty in the system [53]. As a result, nuclear energy plays an increasingly important role as emissions limits tighten. Nuclear's share of annual energy generation rises from $7.8 \%$ and $18.9 \%$ under the 200 and $150 \mathrm{tCO} 2 / \mathrm{GWh}$ emissions limits, respectively, to $40.5 \%$ under $100 \mathrm{tCO} 2 / \mathrm{GWh}$ and $67.6 \%$ under the 50 tCO2/GWh limit. By operating in a flexible manner [25] [26] [27] [28] [29], nuclear units provide a flexible base of zero-carbon energy supplies, providing operating reserves and helping minimize curtailment of wind and solar resources.

\subsection{The impact of energy storage on electricity mix and cost}

The addition of energy storage to the system substantially changes the economically optimal low-carbon portfolio of generating resources and the cost of supplying electricity, as illustrated in Fig. 4 and 5 below. We model two different energy storage capacities: a 2-hour storage capacity, broadly consistent with Li-ion battery systems (left panel), and a 10-hour storage capacity (right panel), consistent with pumped hydroelectric storage [36] [37], as discussed in Section 2.2.

It is important to note that the cost of storage itself is not included in the average generation cost of electricity metric presented thus far. We therefore introduce a new metric accounting for the total system cost (TSC) of supplying electricity for the year-including the cost of storage-, defined as the sum of the $T G C$ and the annuity corresponding to the cost of the storage capacity exogenously added to the system:

$$
T S C=T G C+\text { cost of storage (annuity), } \quad[\mathrm{USD}]
$$


Analogously to the $A G C$, we define the average system cost $(A S C)$ as the quotient between the total system costs (TSC) and the total annual load:

$$
A S C=\frac{T S C}{\Theta \cdot \sum_{h=1}^{H} D_{h}}, \quad[\mathrm{USD} / \mathrm{MWh}]
$$

Under perfect competition, the $A S C$ would be equivalent to the average price of electricity that consumers would ultimately have to pay—excluding the cost of transmission and distribution.

The future costs of energy storage systems are uncertain, particularly for emerging technologies like batteries. To facilitate comparison with current and future forecasted capital costs of Li-ion storage (764 and $536 \mathrm{USD} / \mathrm{kWh}$ respectively ${ }^{4}$ ) and maximum and minimum capital cost estimates of pumped-hydroelectric storage (250 and $100 \mathrm{USD} / \mathrm{kWh}$ respectively ${ }^{5}$ ), we report for each storage duration two average system cost estimates (Fig. 4 and 5). Table A.3 in Appendix A presents a detailed calculation of the storage cost annuity used to derive the average system cost $(A S C)$.

\footnotetext{
${ }^{4}$ These values are consistent with the cost assumptions presented in the cost-benefit results in Section 3.5 and the cost annuity calculation in Table A.3.

${ }^{5}$ These values are consistent with the cost assumptions presented in the cost-benefit results in Section 3.5 and the cost annuity calculation in Table A.3.
} 


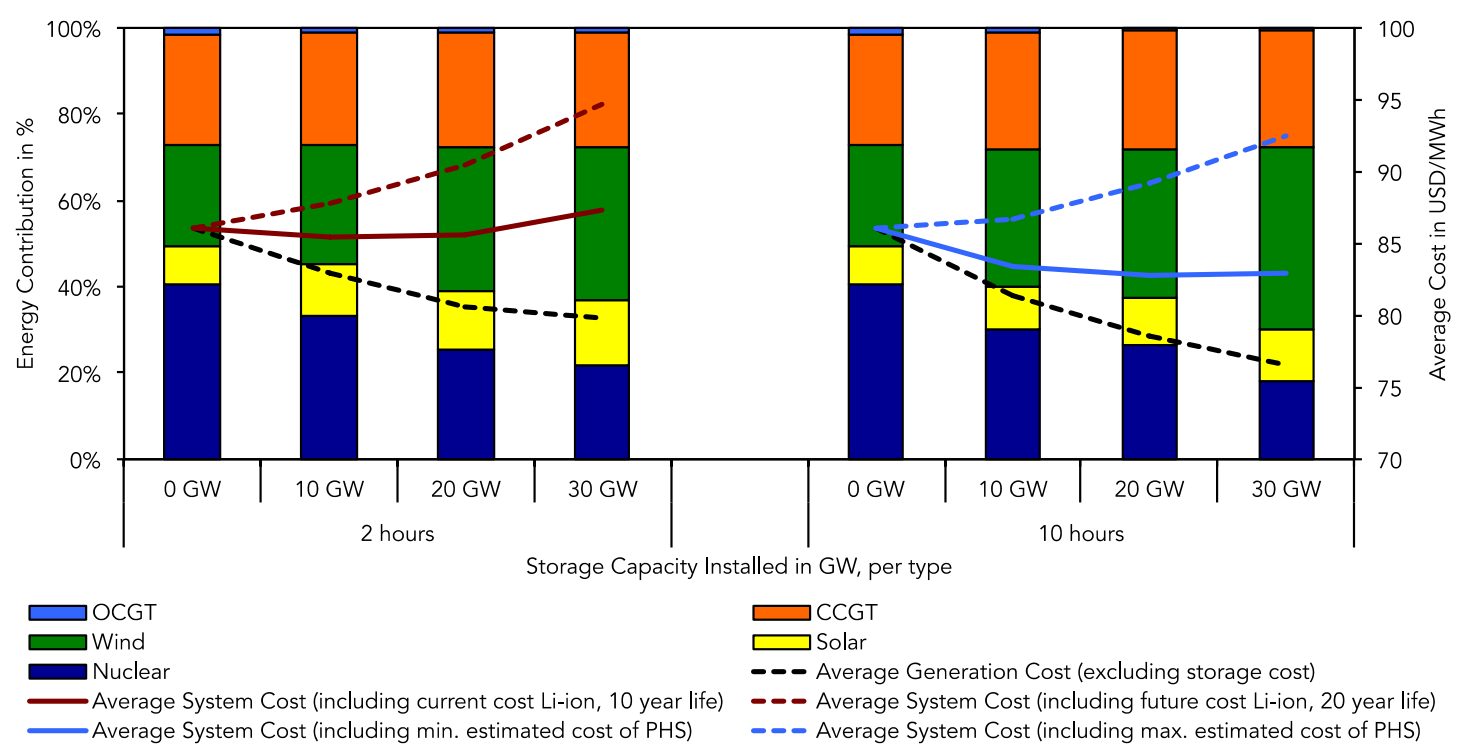

Figure 4 | Impact of energy storage on energy contribution, average generation cost (excluding the cost of energy storage, in black) and average system cost (including the cost of 2-hour and 10-hour storage, in red and blue respectively) under emissions limit of $100 \mathrm{tCO2/GWh.} \mathrm{2-COLUMN} \mathrm{FITTING} \mathrm{IMAGE}$

Energy storage helps reduce average electricity generation costs primarily by increasing the utilization of the least-expensive low-carbon resource, which in our analysis are wind and solar. However, under a carbon emissions limit of $100 \mathrm{tCO} / \mathrm{GWh}$, average system costs inclusive of energy storage costs (Fig. 4 and 5) actually increase, not decrease, in most cases. To reduce total system costs, 2-hour storage costs must improve relative to today's Li-ion costs, and 10-hour storage system costs must fall along the low end of current pumped storage hydro costs. We discuss the economic value of storage in more detail for all other carbon emissions limits studied and present implications for storage technology development cost targets in section 3.5. 


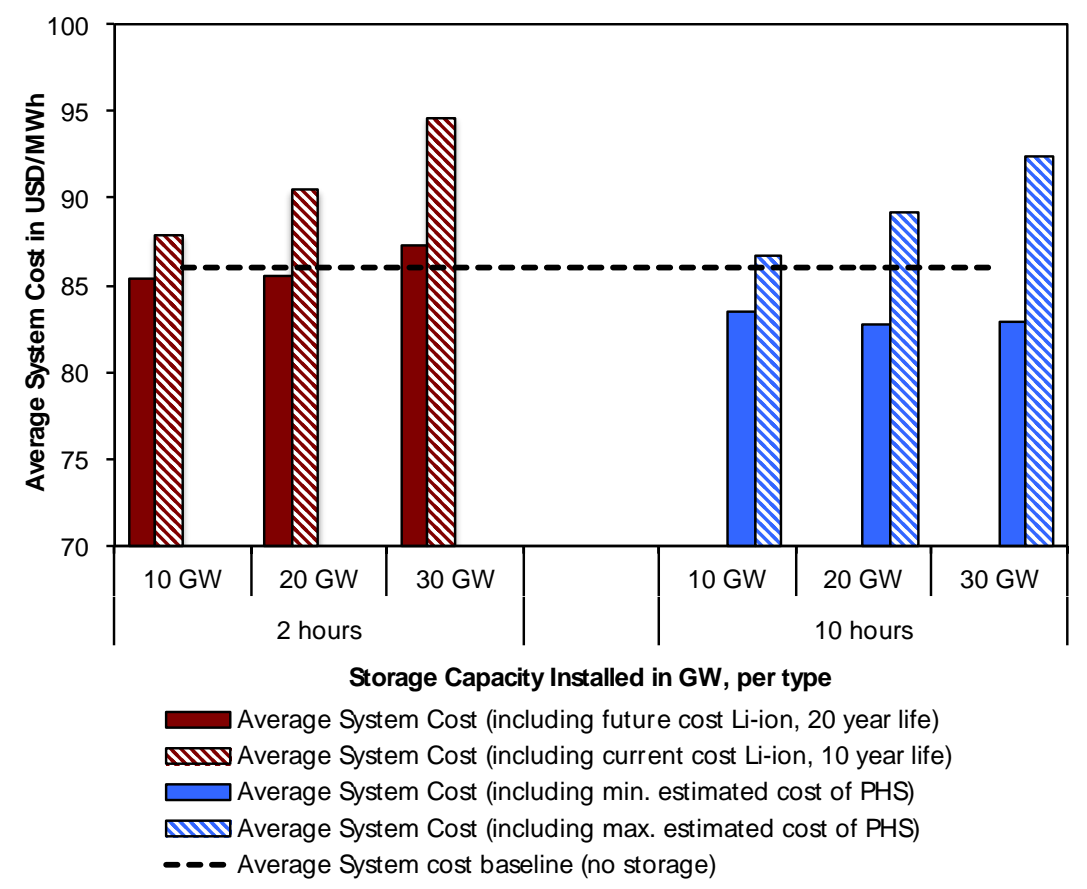

Figure 5 | Impact of energy storage on average system cost under emissions limit of 100 tCO2/GWh. With perfect competition the average system cost could be interpreted as the average electricity price. 1-COLUMN FITTING IMAGE

Given this study's cost assumptions (see Section 3.1), storage reduces curtailment of wind and solar increasing their utilization and attractiveness at higher penetration levels. Increasing storage capacity thus increases the share of variable renewable resources for a given emissions limit and correspondingly reduces the contribution from nuclear. Nuclear's share under the 100 $\mathrm{tCO} 2 / \mathrm{GWh}$ limit is approximately halved, for example, from $40.5 \%$ without storage to a low of $21.6 \%$ with $30 \mathrm{GW}$ of 2-hour duration storage and $17.9 \%$ with $30 \mathrm{GW}$ of 10 -hour duration storage, respectively (Fig. 4). Under the same emissions limit, wind and solar's combined contribution rises, meanwhile, from $32.3 \%$ without storage to a high of $50.7 \%$ and $54.7 \%$ with 30 GW of 2-hour and 10-hour storage, respectively.

In addition, Fig. 4 shows that the duration of energy storage capacity has a very different impact on the optimal share of wind and solar. For an equal storage power capacity, a longerduration energy reservoir increases the share of wind power relative to the shorter-duration 
storage scenarios, and vice versa. Under the $100 \mathrm{tCO}_{2} / \mathrm{GWh}$ and $30 \mathrm{GW}$ storage case, for example, wind and solar make up $42.5 \%$ and $12.2 \%$ of total energy generation, respectively, with 10-hour storage and $35.5 \%$ and $15.2 \%$ respectively with the shorter-duration 2-hour storage. This difference is driven by the different patterns of wind and solar variability and their correlation with electricity demand, as illustrated in Fig. 6-7. While a 2-hour battery is sufficient to store renewable energy production to meet the afternoon peak in load as solar production falls off (Fig. 6), a longer-duration storage option is better suited to shift wind energy production overnight to supply daytime demand (Fig. 7).

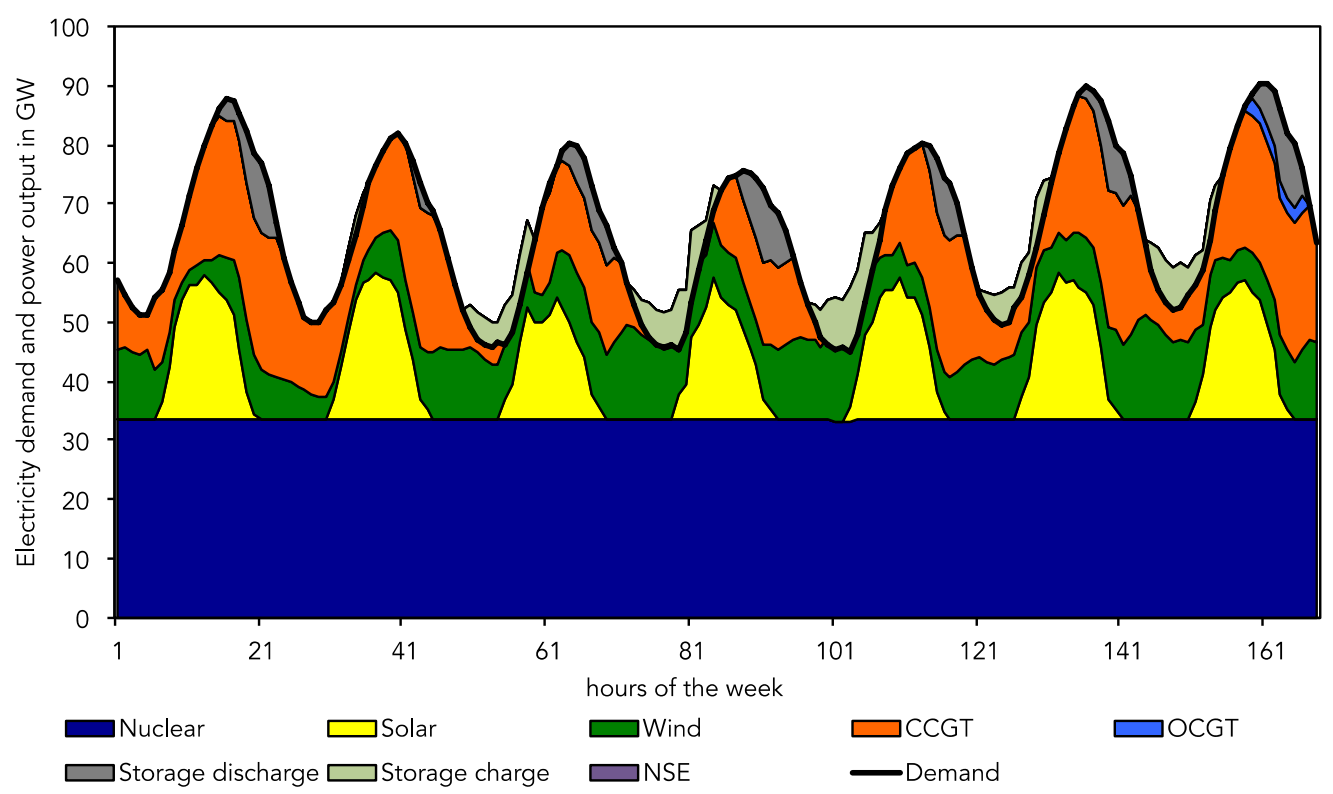

Figure 6 | Example of dispatch in week \#27 under 100tCO2/GWh emissions limit and with $30 \mathrm{GW}$ of storage with two-hour storage capacity. 1 or 2-COLUMN FITTING IMAGE 


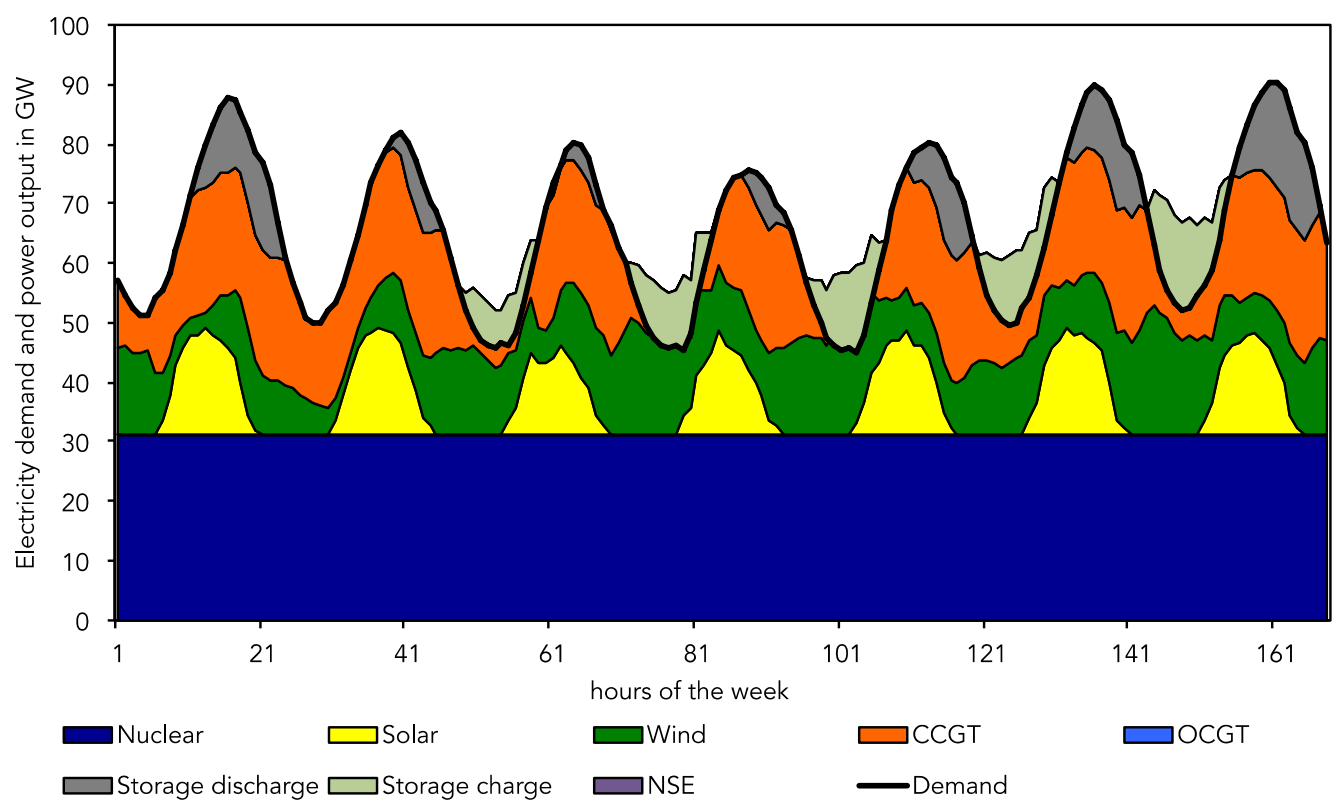

Figure 7 | Example of dispatch in week \#27 under 100tCO2/GWh emissions limit and with $30 \mathrm{GW}$ of storage with ten-hour storage capacity. 1 or 2-COLUMN FITTING IMAGE

Energy storage also competes directly with OCGTs to provide operating reserves and meet peak power demands. As a result, combustion turbine capacity declines steadily as energy storage capacity increases. Under the $100 \mathrm{tCO} / \mathrm{GWh}$ emissions limit, for example, storage displaces OCGT capacity nearly one-for-one, with OCGT capacity falling from $27.5 \mathrm{GW}$ to $4.6 \mathrm{GW}$ or 7.8 $\mathrm{GW}$ as storage capacity increases from $0-30 \mathrm{GW}$ with a 10-hour or 2-hour storage duration, respectively. In contrast, installed capacity and utilization of CCGTs are largely unaffected by the addition of energy storage. While wind energy has a lower levelized cost of delivered electricity than CCGTs in this study ${ }^{6}$, once the marginal value of wind falls sufficiently, the model essentially deploys and utilizes CCGTs until the emissions limit is reached, before then turning to more expensive zero carbon resources.

\footnotetext{
${ }^{6}$ At an average capacity factor of $73.5 \%$ in the unconstrained emissions case, CCGTs have a levelized cost of USD 74.51/MWh, as compared to 60.31/MWh for wind.
} 


\subsection{The impact of relying exclusively on renewables}

Since some countries do not consider nuclear power as an option for their future electricity mix, we performed an additional analysis of the seven storage scenarios with the $100 \mathrm{t} / \mathrm{GWh}$ emissions limit after excluding nuclear power as an eligible generation technology. First, we note that in the no storage case, our model was unable to produce a feasible electricity portfolio to comply with the $100 \mathrm{tCO}_{2} / \mathrm{GWh}$ emissions limit. Without a zero-carbon source of system flexibility, natural gas-fired units are necessary to meet the operating reserve requirements commensurate with high penetrations of wind and solar energy, and these gas-fired units emit too much $\mathrm{CO}_{2}$ to meet the relatively strict emissions limit. In effect, a sufficient level of low-carbon system flexibility (be it storage, demand response, hydropower, or some other resource) is necessary to meet technical power system operational requirements under strict emissions limits if variable renewable resources are the chief means of achieving decarbonization.

The model produced feasible results for each of the cases including energy storage. Fig. 8 shows the economically optimal low-carbon portfolio of generating resources for these cases, as well as the average generation and system costs achieved in the different storage capacity scenarios (see also Fig. 9 for a more detailed comparison of average system costs). As above, the energy contribution from CCGTs remains almost constant as its contribution is effectively limited by the carbon emissions constraint imposed on the system. The optimal share of wind and solar power for each of the two energy storage technology cases studied-2-hour and 10-hour storage - is also approximately unchanged, with wind supplying roughly $50 \%$ and solar $20 \%$ of annual electricity in each case. While the total amount of energy storage capacity improves renewable utilization rates, it barely changes their relative importance in the energy generation mix. However, by reducing curtailment (see Fig. 10) and improving the utilization of wind and solar resources, increasing levels of energy storage reduce the total installed capacity of wind and solar required, driving down overall generation costs. As Fig. 8 and 9 illustrate, cost reductions 
due to storage saturate at $20 \mathrm{GW}$ for the 2-hour storage technology, whereas there is also a significant incremental cost reduction at the $30 \mathrm{GW}$ level for 10 -hour storage.

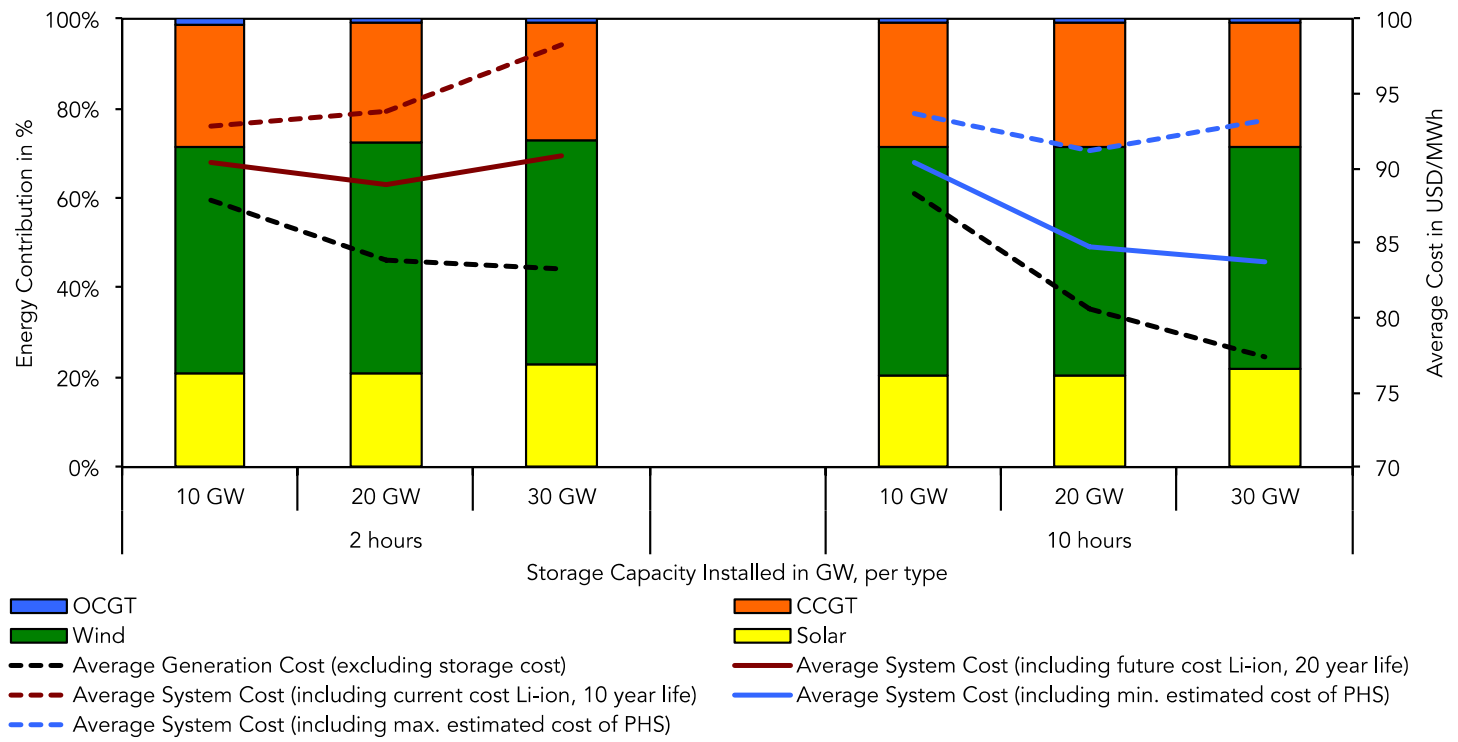

Figure 8 | Impact of energy storage on energy contribution and average generation cost (excluding the cost of energy storage) and average system cost (including the cost of 2-hour and 10-hour storage, in red and blue respectively) under emissions limit of $100 \mathrm{tCO} / \mathrm{GWh}$ and no availability of flexible nuclear. 2-COLUMN FITTING IMAGE

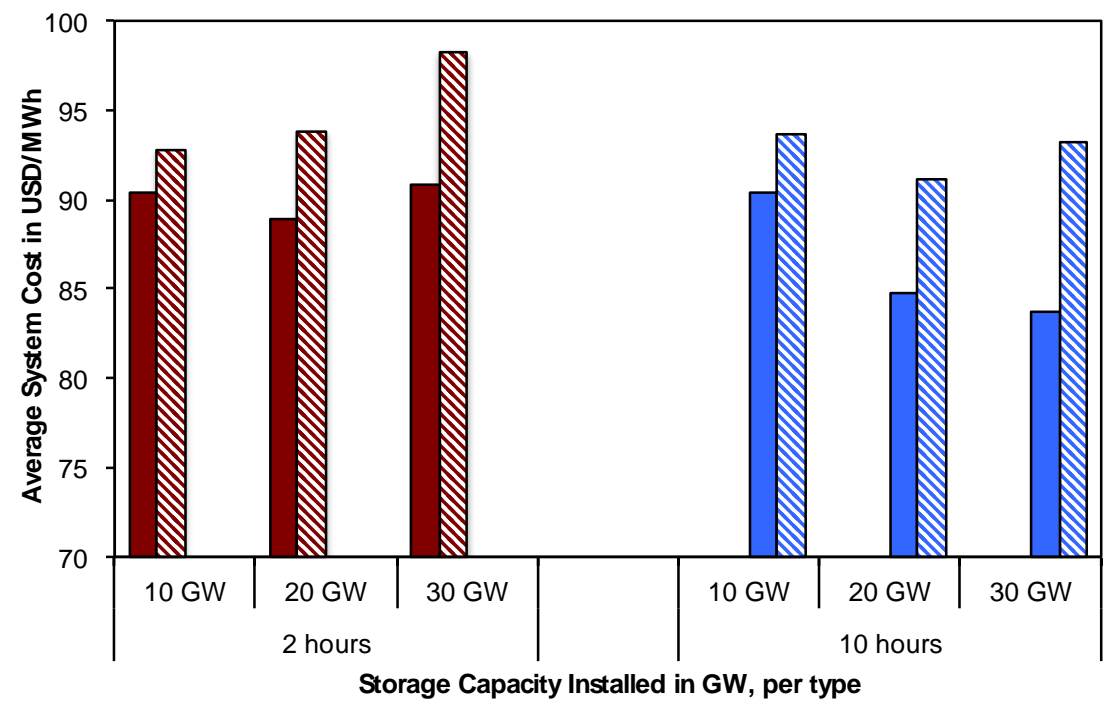

- Average System Cost (including future cost Li-ion, 20 year life) बAverage System Cost (including current cost Li-ion, 10 year life) $\square$ Average System Cost (including min. estimated cost of PHS) $\checkmark$ Average System Cost (including max. estimated cost of PHS)

Figure 9 | Impact of energy storage on average system cost under emissions limit of 100 tCO2/GWh and no availability of flexible nuclear. With perfect competition the average system cost could be interpreted as the average electricity price. 1-COLUMN FITTING IMAGE 
Comparing the two cases with and without nuclear (Fig. 4 and Fig. 8, respectively) demonstrates that excluding nuclear power from the low-carbon power mix increases overall system costs (given the costs assumptions employed herein). With $10 \mathrm{GW}$ of energy storage installed, including nuclear reduces total generation costs by $8.6 \%$ under the 10 -hour storage technology case and $6.0 \%$ under the 2-hour technology case. This finding indicates that renewable energy and flexible nuclear power are likely to coexist in an economically optimal low-carbon electricity system, even with large amounts of energy storage. Nevertheless, if storage becomes sufficiently affordable, the role of wind and solar expands and the relative importance of nuclear power declines.

\subsection{The impact of energy storage on renewable curtailment}

Oftentimes it is not technically feasible or economically efficient to utilize all renewable energy available in power systems with a large share of renewable generation, and a fraction of this renewable energy available needs to be curtailed. Hourly curtailment decisions are endogenously determined by the model consistent with its objective function and technical constraints. The total renewable energy curtailed over the course of one year can be expressed in terms of the total renewable energy available with the rate of curtailment, which is given by the following expression:

$$
R C=100 \cdot \frac{\sum_{h=1}^{H}\left(p^{W I N D} \cdot C F_{h}^{W I N D}+p^{\text {SOLAR }_{C}} \cdot F_{h}^{S O L A R}-x_{h}^{W I N D}-x_{h}^{S O L A R}\right)}{\sum_{h=1}^{H}\left(p^{W I N D} \cdot C F_{h}^{W I N D}+p^{S O L A R} \cdot C F_{h}^{S O L A R}\right)} \quad[\%]
$$

where $p^{\text {WIND }}$ is the wind power capacity installed in MWs; $p^{\text {SOLAR }}$ is the solar capacity installed in MWs; $C F_{h}^{W I N D}$ is the capacity factor of wind — or wind availability — during hour $h$ in per unit; $C F_{h}^{\text {SOLAR }}$ is the capacity factor of solar — or solar availability — during hour $h$ in per unit; $x_{h}^{W I N D}$ is the wind generation during hour $h$ in MWs; and $x_{h}^{\text {SOLAR }}$ is the solar generation during hour $h$ in MWs. 
The importance of energy storage is magnified in a scenario predominately reliant on variable renewables to decarbonize the power system. With the addition of sufficient energy storage, it becomes technically feasible to meet a $100 \mathrm{tCO}_{2} / \mathrm{GWh}$ limit with only wind, solar, and gas-fired plants, as discussed above. However, up to $13.2 \%$ of wind and solar generation is wasted due to curtailment if only $10 \mathrm{GW}$ of energy storage is installed (Fig. 10). Renewable curtailment declines as storage capacity increases, but it is still a substantial $4-8 \%$ at $30 \mathrm{GW}$ of storage, depending on the storage duration. Fig. 10 also shows that a diversified portfolio that includes flexible nuclear energy would reduce renewable curtailment to levels below $2.4 \%$ under a $100 \mathrm{tCO}_{2} / \mathrm{GWh}$ emissions limit. The reductions in renewable curtailments lower the costs of meeting this emissions limit. Note also that the evolution of renewable curtailment with the amount of energy storage capacity deployed does not fall monotonically in the case that includes flexible nuclear power in the mix. This non-monotonicity is due to the fact that thermal power investments in general and nuclear power units in particular are discrete and 'lumpy' (e.g., investments in new dual-reactor nuclear plants are made in 2,230 megawatt increments), which might create curtailment 'jumps' whenever nuclear capacity is substituted by renewables in the solution. 


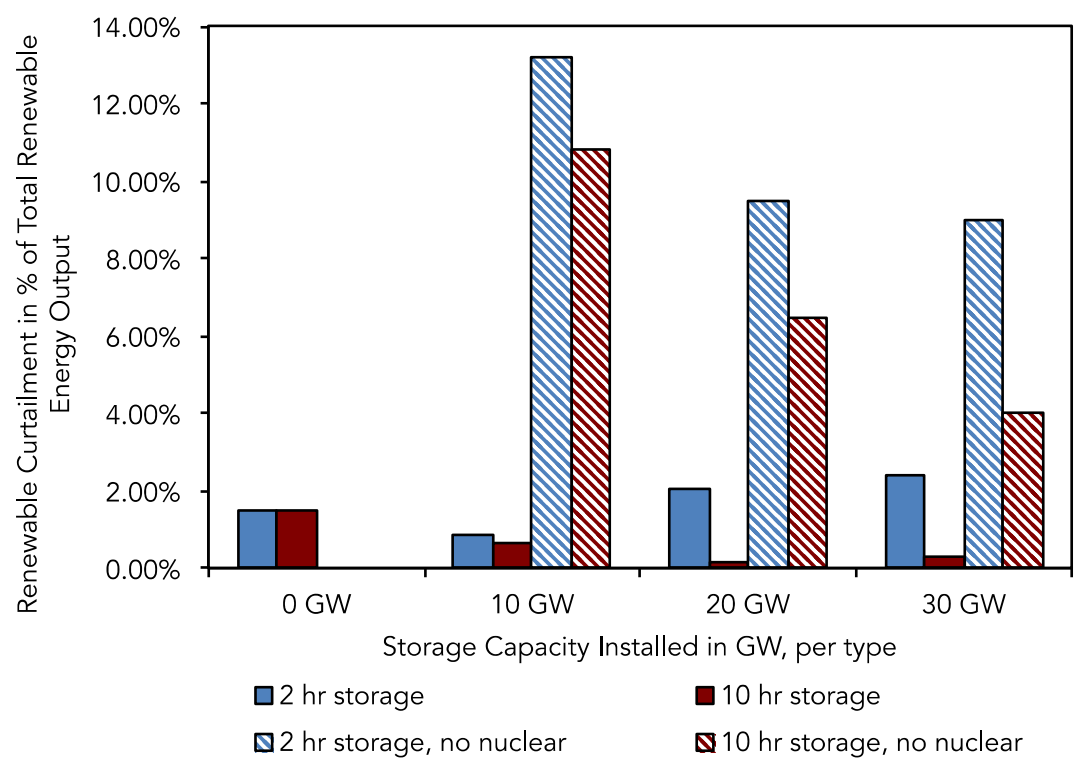

Figure 10 | Renewable curtailment as a percentage of the total renewable energy output for the two energy storage technology cases -2 hour and 10 hour storage-, and a $100 \mathrm{tCO2/GWh}$ carbon emissions limit. Note that for the scenario of $0 \mathrm{GW}$ of storage capacity installed, the solution with no flexible nuclear is infeasible and no results are shown in the figure. 1-COLUMN FITTING IMAGE

\subsection{The economic value of energy storage}

Fig. 11 and Fig. 12 illustrate the value for each $10 \mathrm{GW}$ increment of additional storage capacity — defined as the avoided electricity generation investment and operations cost—for each of the two storage technology options analyzed (2-hour and 10-hour of storage). To enable comparison to cost projections for energy storage technologies, we convert the annual avoided generation costs to net present value avoided costs per kWh of energy storage capacity installed. Results on the marginal value of storage (MVS) are sensitive to the assumed usable lifetime of the storage asset $(T)$ in years, so we present results for a 10,20, and 30-year usable life, applying a $10 \%$ discount rate in each case. The MVS between an initial storage capacity $S O$ and a final storage capacity $S 1$ is therefore the net present value of the difference in total generation costs ( $T G C$ in USD) between the case with $S O \mathrm{kWh}$ of energy storage and the case with $S 1 \mathrm{kWh}$ of energy storage, divided by the difference in storage capacity between $S I$ and $S 0$ :

$$
M V S_{S 0-s 1}=\sum_{t=1}^{T} \frac{\left(T G C_{S 0}-T G C_{S 1}\right) /(S 1-S 0)}{(1+10 \%)^{t}}[\mathrm{USD} / \mathrm{kWh}]
$$


Fig. 11 presents results for the 2-hour storage technology cases, representative for many electrochemical battery storage technologies. Assuming a 10-year asset life, the first $10 \mathrm{GW}$ of 2hour duration storage avoids USD 286-572 in generation costs per installed $\mathrm{kWh}$ of storage capacity (depending on emissions limit). The marginal value of storage declines rapidly, however, falling to USD 193-367 per kWh at $20 \mathrm{GW}$ installed capacity and USD 40-208 per kWh at $30 \mathrm{GW}$. If the storage asset lasts for 20 or 30 years, the marginal value increases $39 \%$ and $53 \%$ respectively.

For comparison, current best-in-class utility-scale Li-ion storage systems cost approximately USD 764/kWh installed, including approximately USD 250/kWh for the battery pack and USD $514 / \mathrm{kWh}$ for balance of system (power electronics, racking, connection to the grid, etc.) [36] [54]. Expected to last for only 10 years (3-4,000 cycles with an average cycling pattern of one full cycle per day), these systems remain too costly in comparison to estimated avoided generation costs (Fig. 11) regardless of the stringency of emissions limits.

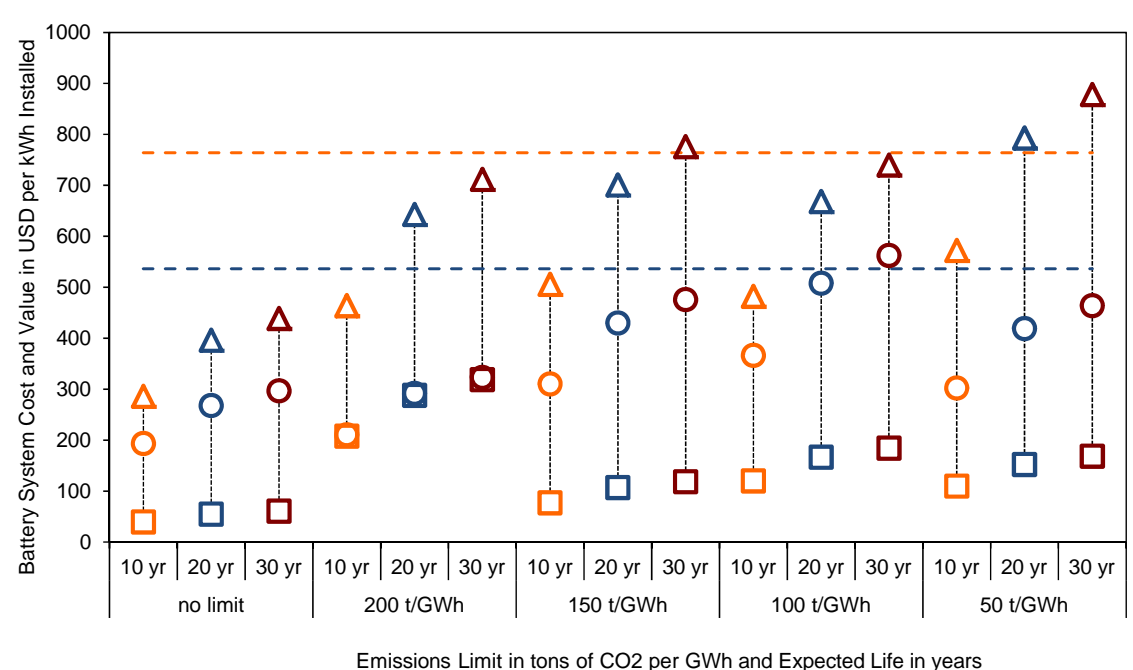
- - - Current estimated cost of Li-ion battery systems ( $10 \mathrm{yr}$ life)
- - - Future potential costs of Li-ion battery systems ( 20 yr life)
$\Delta$ 0-10 GW, $10 \mathrm{yr}$ life
- $10-20 \mathrm{GW}, 10 \mathrm{yr}$ life
ㅁ $20-30 \mathrm{GW}, 10 \mathrm{yr}$ life
$\Delta \quad 0-10 \mathrm{GW}, 20 \mathrm{yr}$ life
- $10-20 \mathrm{GW}, 20 \mathrm{yr}$ life
$20-30 \mathrm{GW}, 20 \mathrm{yr}$ life
$\Delta \quad 0-10 \mathrm{GW}, 30 \mathrm{yr}$ life
- $10-20 \mathrm{GW}, 30 \mathrm{yr}$ life
- $20-30 \mathrm{GW}, 30 \mathrm{yr}$ life

Figure 11 | Cost-benefit of energy storage: system value of 2-hour energy storage capacity for different carbon emissions goals and current and potential future cost for $\mathrm{Li}$-ion battery systems for comparison. Different markers reflect different storage penetration levels, and different colors reflect different expected asset lifespan. 2-COLUMN FITTING IMAGE

Looking ahead, the U.S. Department of Energy targets a capital cost of USD 125/kWh for Li-ion battery packs by 2022 [55]. If a $20 \%$ reduction in balance of system costs can also be 
achieved, that would bring total installed system costs to roughly USD 536/kWh. Combined with a usable life of 20 years (e.g. > 7,000 cycles), Fig. 11 indicates that such systems would deliver sufficient value under emissions limits to justify deployment at up to 10-20 GW scale, depending on the emissions limit. Assuming a 20-year storage asset life, the net present value of generation costs avoided by the first $10 \mathrm{GW}$ of two-hour storage technology installed ranges from USD $642 / \mathrm{kWh}$ of installed storage capacity under the $200 \mathrm{tCO} 2 / \mathrm{GWh}$ emissions limit to USD 793/kWh installed under the $50 \mathrm{tCO} 2 / \mathrm{GWh}$ limit, exceeding the estimated cost of this improved battery system by roughly $20-48 \%$. Much more dramatic cost reductions (i.e., an $80-85 \%$ reduction from current system costs) would be necessary to justify storage deployment at $30 \mathrm{GW}$ or greater scale based on avoided generation costs.
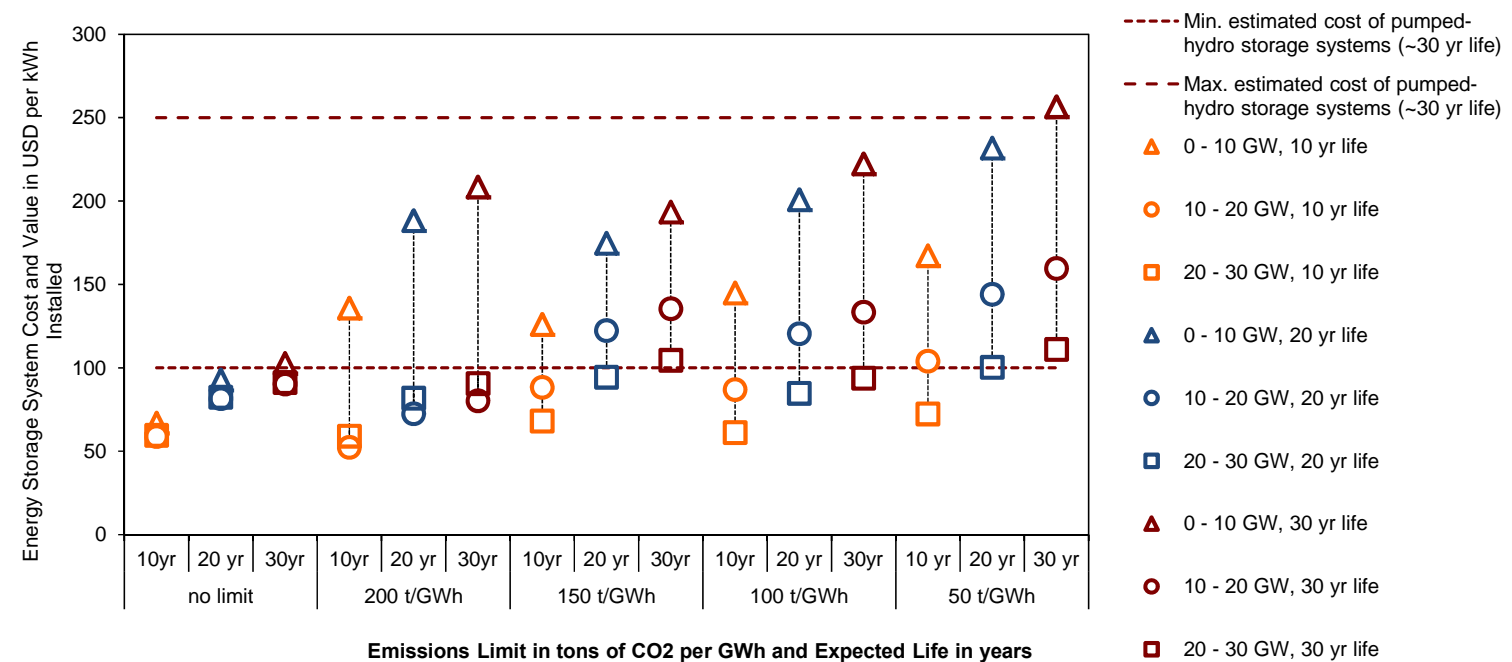

Figure 12 | Cost-benefit of energy storage: system value of 10-hour energy storage capacity for different carbon emissions goals and minimum and maximum current estimated cost of pumped-hydro storage systems ( 30 year life) for comparison. Different markers reflect different storage penetration levels, and different colors reflect different expected asset lifespan. 2-COLUMN FITTING IMAGE

Fig. 12 presents the estimated value of energy storage for the different 10-hour energy storage cases. Assuming a 30-year financial life of the asset, results show that the first $10 \mathrm{GW}$ of 10-hour duration storage avoids USD 103-257 per installed kWh (depending on emissions limit) 
in generation costs. The marginal value of storage declines to USD 80-160/kWh at $20 \mathrm{GW}$ installed capacity and USD $91-112 / \mathrm{kWh}$ at $30 \mathrm{GW}^{7}$

For comparison, we present the maximum and minimum estimated costs of pumped-hydro storage (USD 100-250/kWh installed) as a reference against the value calculated for the 10-hour generic storage technology, as pumped-hydro storage systems could offer storage capabilities of this duration [36] [37]. As Fig. 12 illustrates, 10-hour energy storage capacity systems with 30 years of expected life provide sufficient value to justify deployment under the lower range of current estimates of pumped-hydro storage system costs. Yet, the availability of pumped-hydro storage depends very much on the geographical characteristics of the targeted location, which certainly limit their deployment potential. Commercially available flow battery technologies, which may offer similar durations of energy storage, remain nascent and have different characteristics that may not be directly comparable to the values presented above.

\section{Discussion}

Energy storage has been presented in many studies as a necessary element to significantly reduce the carbon footprint of the electricity sector. Indeed, our results indicate that meeting strict emissions reduction targets with variable renewable energy sources alone may be impossible without scalable energy storage or another zero-carbon source of operating flexibility. If flexible nuclear is precluded from our set of eligible technologies, our model cannot produce a feasible electricity portfolio to comply with a $100 \mathrm{tCO}_{2} / \mathrm{GWh}$ or tighter limit without including energy storage. In contrast, if dispatchable nuclear power plants are included in the eligible set of resources, emissions limits as low as $50 \mathrm{tCO}_{2} / \mathrm{GWh}$ are achieved at modest incremental cost even

\footnotetext{
${ }^{7}$ Note that the small and non-monotonic increment in marginal value between $20 \mathrm{GW}$ and $30 \mathrm{GW}$ compared to the value between $10 \mathrm{GW}$ and $20 \mathrm{GW}$ is created by the lumpiness of the generation investment decisions, as the model decides on investments in individual plants, some of which are quite large (i.e. 2,230 MW dual reactor nuclear plant).
} 
without storage. In short, our results indicate that energy storage may be essential to enable climate mitigation strategies dependent exclusively on very high shares of wind or solar energy, but storage is not a requisite if a more diverse mix of flexible, low-carbon power sources is considered.

Our results also show that if storage technologies meet future technology performance and cost goals (i.e. extended cycle life and cost reductions), electrochemical energy storage could become a cost-effective contributor to very low-carbon power systems (Fig. 6). At the same time, the diminishing marginal value of energy storage means that the economically optimal penetration level of storage will be limited unless costs continue to decline well beyond current targets or in specific locations where storage systems deliver significant additional value to electricity systems not considered in this paper, such as avoidance of transmission or distribution costs.

\section{Conclusion}

The results presented in this work help inform the current debate about the value and role of energy storage in decarbonizing electricity systems. Using a capacity expansion model with detailed unit commitment constraints we quantify the value of different capacity levels of 2-hour and 10-hour energy storage under stringent carbon emissions limits.

We first show that there is no silver bullet to decarbonize the electricity sector: the least-cost generation mix includes a diverse mix of resources and wind, solar and flexible nuclear technologies co-exist in the optimal low-carbon generation portfolio, regardless of the level of energy storage. Under an emissions limit of $100 \mathrm{tCO}_{2} / \mathrm{GWh}$, nuclear's contribution to total energy supply ranges from $18-40 \%$, depending on the amount of energy storage installed, while solar and wind shares are in the $9-15 \%$ and $23-43 \%$ ranges, respectively. Likewise, flexible nuclear contributes $52-68 \%$ under a tighter $50 \mathrm{tCO}_{2} / \mathrm{GWh}$ limit while solar contributes $7-14 \%$ and wind 12-19\%, depending on the storage capacity. Excluding dispatchable low-carbon resources-i.e. 
flexible nuclear power in this analysis - from the portfolio raises costs by up to $8.6 \%$ and increases the relative importance of energy storage, or other sources of emissions-free flexibility, to integrate variable renewable energy sources and meet the need for operating reserves.

We find that under strict emissions limits, corresponding to a roughly $63-91 \%$ reduction from today's prevailing emissions rates, energy storage can reduce generation costs by increasing the utilization of installed resources and enabling greater penetration of the lowest cost carbonfree resources. Total generation costs—excluding the cost of energy storage- fall by $7-11 \%$ as up to $30 \mathrm{GW}$ of energy storage is installed under a $100 \mathrm{tCO}_{2} / \mathrm{GWh}$ emissions limit and up to $12 \%$ under a $50 \mathrm{tCO}_{2} / \mathrm{GWh}$ limit. However, energy storage is only strictly necessary to meet tight emissions limits in the absence of flexible dispatchable zero-carbon generation technologies.

The value of longer duration (i.e., 10-hour) energy storage resources appears high enough to justify the deployment of pumped-hydro resources at current costs, but opportunities to deploy pumped-hydro storage is geographically limited. Conversely, the value of shorter-duration (i.e. 2hour) storage technologies, such as Li-ion batteries, is only justified by generation cost savings under the most stringent carbon emissions limits, and even then, only at low storage penetration levels. Hence, continued innovation and cost declines for Li-ion batteries and other electrochemical energy storage technologies will be necessary to economically justify large-scale deployment in future low-carbon power systems.

\section{Abbreviations and nomenclature}

$A G C \quad$ average generation costs in USD/MWh

ASC average system costs in USD/MWh

$C_{i}^{F I X} \quad$ annualized fixed cost of plant $i$ in USD $/ \mathrm{kW}-\mathrm{yr}$

$C_{i}^{V A R} \quad$ variable cost of plant $i$ in USD/MWh

$C F_{h}^{S O L A R} \quad$ solar power capacity factor during hour $h$ in per unit

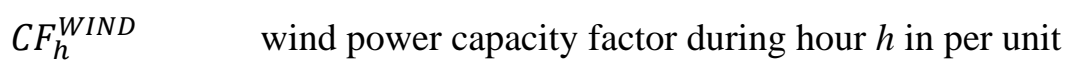

CCGT combined cycle gas turbine 


\section{Acknowledgements}

The authors would like to thank J.I. Perez-Arriaga and two anonymous reviewers for helpful comments and review. The submitted manuscript has been created by UChicago Argonne, LLC, Operator of Argonne National Laboratory (“Argonne”). Argonne, a U.S. Department of Energy Office of Science laboratory, is operated under Contract No. DE AC02-06CH11357. J.D.J. also gratefully acknowledges support from the U.S. National Science Foundation Graduate Research Fellowship program.

\section{References}

[1] IPCC, "Summary for Policymakers, Climate Change 2014: Mitigation of Climate Change. Contribution of Working Group III to the Fifth Assessment Report of the Intergovernmental Panel on Climate Change," Intergovernmental Panel on Climate Change, Cambridge, UK, 2014.

[2] John P. Weyant, Geoffrey J. Blanford, Volker Krey, Leon Clarke, Jae Edmonds, Allen Fawcett, Gunnar Luderer, Keywan Riahi, Richard Richels, Steven K. Rose, Massimo Tavoni, \& Detlef P. van Vuuren Elmar Kriegler, "The role of technology for achieving climate policy objectives: overview of the EMF 27 study on global technology and climate policy strategies," Climatic Change, vol. 123, pp. 353-367, 2014.

[3] IEA, "Energy Technology Perspectives 2015: Mobilising Innovation to Accelerate Climate Action," International Energy Agency, Paris France, 2015.

[4] P. Denholm, E. Ela, B. Kirby, and M. Milligan, "The Role of Energy Storage with Renewable Electricity Generation," National Renewable Energy Laboratory, 2010.

[5] Ramteen Sioshansi, Paul Denholm, Thomas Jenkin, and Jurgen Weiss, "Estimating the Value of Electricity Storage in PJM: Arbitrage and Some Welfare Effects," Energy Economics, vol. 31, no. 2, pp. 269-277, 2009.

[6] Anastasia Shcherbakovaa, Andrew Kleitb, and Joohyun Chob, "The Value of Energy Storage in South Korea's Electricity Market: A Hotelling Approach," Applied Energy, vol. 125, pp. 93-102.

[7] Kyle Bradbury, Lincoln Pratson, and Dalia Patiño-Echeverri, "Economic Viability of Energy Storage Systems Based on Price Arbitrage Potential in Real-Time U.S. Electricity Markets," 
Applied Energy, vol. 114, pp. 512-519, 2014.

[8] Dylan McConnell, Tim Forcey, and Mike Sandiford, "Estimating the Value of Electricity Storage in an Energy-Only Wholesale Market," Applied Energy, vol. 159, pp. 422-432, 2015 .

[9] P. Denholm and M. Hand, "Grid flexibility and storage required to achieve very high penetration of variable renewable electricity," Energy Policy, vol. 39, no. 3, pp. 1817-1830, 2011.

[10] Joohyun Cho and Andrew N. Kleit, "Energy Storage Systems in Energy and Ancillary Markets: A Backwards Induction Approach," Applied Energy, vol. 147, pp. 176-183, 2014.

[11] Trishna Das, Venkat Krishnan, and James D. McCalley, "Assessing the Benefits and Economics of Bulk Energy Storage Technologies in the Power Grid," Applied Energy, vol. 139, pp. 104-118, 2015.

[12] Mary Black and Goran Strbac, "Value of Bulk Energy Storage for Managing Wind Power Fluctuations," IEEE Transactions on Energy Conversion, vol. 22, no. 1, pp. 197-205, March 2007.

[13] IEA, "The Power of Transformation Wind, Sun and the Economics of Flexible Power Systems," International Energy Agency, Paris, 2014.

[14] Eric Cutter, Ben Haley, Jeremy Hargreaves, and Jim Williams, "Utility Scale Energy Storage and the Need for Flexible Capacity Metrics," Applied Energy, vol. 124, pp. 274-282, 2014.

[15] GE Energy, "Western Wind and Solar Integration Study," Golden, CO, SR-550-47434, 2010.

[16] A. Tuohy and M. O’Malley, "Pumped storage in systems with very high wind penetration," Energy Policy, vol. 39, no. 4, pp. 1965-1974, 2011.

[17] E. S. Hittinger and I. M. L. Azevedo, "Bulk Energy Storage Increases United States Electricity System Emissions," Environmental Science and Technology, vol. 49, no. 5, pp. 3203-3210, 2015.

[18] R. Lueken and J. Apt, "The effects of bulk electricity storage on the PJM market," Energy Systems, no. 5, p. 1-14, 2014.

[19] A.A. Solomon, Daniel M. Kammen, and D. Callaway, "The Role of Large-Scale Energy Storage Design and Dispatch in the Power Grid: A Study of Very High Grid Penetration of Variable Renewable Resources," Applied Energy, vol. 134, pp. 75-89, 2014. 
[20] D. Pudjianto and et al., "Whole-Systems Assessment of the Value of Energy Storage in LowCarbon Electricity Systems," IEEE Transactions on Smart Grid, vol. 5, no. 2, 2014.

[21] A. Mileva, J. Johnston, J. H. Nelson, and D. M. Kammen, "Power system balancing for deep decarbonization of the electricity sector," Applied Energy, vol. 162, pp. 1001-1009, 2016.

[22] H. Safaei and D. Keith, "How much bulk energy storage is needed to decarbonize electricity?," Energy and Environmental Science, 2015.

[23] I. J. Pérez-Arriaga and P. Linares, "Markets vs. Regulation: A Role for Indicative Energy Planning," Energy Journal, p. 13, March 2008.

[24] F. J. de Sisternes, M. D. Webster, and J. I Perez-Arriaga, "The Impact of Bidding Rules on Electricity Markets with Intermittent Renewables," IEEE Transactions on Power Systems, vol. 30, no. 3, pp. 1603-1613, May 2015.

[25] OECD-NEA, "Nuclear Energy and Renewables System Effects in Low-carbon Electricity Systems," OECD Nuclear Energy Agency, Paris, France, 2012.

[26] OECD-NEA, "Technical and Economic Aspects of Load Following with Nuclear Power Plants," OECD Nuclear Energy Agency, Paris, France, 2011.

[27] EPRI, "Program on Technology Innovation: Approach to Transition Nuclear Power Plants to Flexible Operations," Electric Power Research Institute, Palo Alto, CA, 2014.

[28] EUR, "The European Utility Requirement (EUR) document, Revision D," European Utilities Requirements for LWR Nuclear Power Plants, 2012.

[29] Westinghouse, "AP1000 Design Control Document. Chapter 7: Instrumentation and Controls," 2009.

[30] IEA, "CO2 Emissions from Fuel Combustion: Highlights. 2014 Edition," International Energy Agency, Paris, France, 2014.

[31] European Environment Agency. (2014) Overview of the electricity production and use in Europe (ENER 038). [Online]. http://www.eea.europa.eu/data-andmaps/indicators/overview-of-the-electricity-production/assessment-2

[32] EIA, "Annual Energy Outlook 2014," U.S. Energy Information Administration, 2014.

[33] NREL. PV Watts Calculator. [Online]. http://pvwatts.nrel.gov/

[34] DOE, "Wind Vision Report," U.S. Department of Energy, 2015.

[35] DOE, "SunShot Vision Study ," U.S. Department of Energy, 2012.

[36] EPRI \& DOE, "DOE/EPRI Electricity Storage Handbook in Collaboration with NRECA," 
U.S. Department of Energy, 2013.

[37] Xing Luo, Jihong Wang, Mark Dooner, and Jonathan Clarke, "Overview of Current Development in Electrical Energy Storage Technologies and the Application Potential in Power System Operation," Applied Energy, vol. 137, pp. 511-536, 2015.

[38] Botterud A., Levin T., and Koritarov V., "Pumped Storage Hydropower: Benefits for Grid Reliability and Integration of Variable Renewable Energy," Argonne National Laboratory, Report ANL/DIS-14/10 2014.

[39] F. J. de Sisternes, "Investment Model for Renewable Electricity Systems (IMRES): an Electricity Generation Capacity Expansion Formulation with Unit Commitment Constraints," CEEPR Working Paper Series, no. 016, November 2013.

[40] R. Turvey and D. Anderson, Electricity Economics. Essays and Case Studies. Baltimore and London: The World Bank, The Johns Hopkins University Press, 1977.

[41] J. Ma, V. Silva, R. Belhomme, D.S. Kirschen, and L. F. Ochoa, "Evaluating and Planning Flexibility in Sustainable Power Systems," IEEE Transactions on Sustainable Energy, vol. 4, no. 1, pp. 200-209, 2013.

[42] S. Jin, A. Botterud, and S.M. Ryan, "Temporal vs. Stochastic Granularity in Thermal Generation Capacity Planning with Wind Power," IEEE Transactions on Power Systems, vol. 29, no. 5, pp. 2033-2041, 2014.

[43] F. J. de Sisternes and M. D. Webster, "Optimal Selection of Sample Weeks for Approximating the Net Load in Generation Planning Problems," ESD Working Paper Series, 2013. [Online]. http://esd.mit.edu/wps/2013/esd-wp-2013-03.pdf

[44] Ryan Wiser and Mark Bolinger, "2013 Wind Technologies Market Report," Lawrence Berkeley National Laboratory, 2014.

[45] GTM Research, "Solar Market Insight, 2014," 2014.

[46] Matthew Bandyk, "Georgia Power Reveals \$1B Increase in Vogtle Nuclear Project Costs," Transmission and Distribution World, March 2015.

[47] ERCOT, "Hourly Load Data Archives," The Electric Reliability Council of Texas , 2015.

[48] L. Hirth, "The market value of variable renewables: The effect of solar wind power variability on their relative price," Energy Economics, vol. 38, pp. 218-236, 2013.

[49] A. Mills and R. Wiser, "Changes in the Economic Value of Variable Generation at High Penetration Levels: A Pilot Case Study of California," Lawrence Berkeley National 
Laboratory, 2012.

[50] A. Keane and et al., "Capacity Value of Wind Power," IEEE Transactions on Power Systems, vol. 26, no. 2, 2011.

[51] F. D. Munoz and A. D. Mills, "Endogenous Assessment of the Capacity Value of Solar PV in Generation Investment Planning Studies," IEEE Transactions on Sustainable Energy, 2015.

[52] MIT, "The Future of Solar Energy," Massachusetts Institute of Technology, 2015.

[53] H. Holttinen and et al., "Methodologies to Determine Operating Reserves Due to Increased Wind Power ," IEEE Transactions on Sustainable Energy, vol. 3, no. 4, 2012.

[54] GTM Research , "U.S. Energy Storage Monitor," 2015.

[55] B. Nykvist and M. Nilsson, "Rapidly falling costs of battery packs for electric vehicles," Nature Climate Change, vol. 5, pp. 329-332, 2015.

[56] EIA. (2013) Updated Capital Cost Estimates for Utility Scale Electricity Generating Plants. [Online]. http://www.eia.gov/forecasts/capitalcost/pdf/updated_capcost.pdf

[57] MIT, "Managing Large-Scale Penetration of Intermittent Renewables. An MIT Energy Initiative Symposium ," Massachusetts Institute of Technology, 2011.

[58] EIA, "How much carbon dioxide is produced when different fuels are burned? ," U.S. Energy Information Administration, 2015.

[59] N. Stern, "Stern Review on The Economics of Climate Change," HM Treasury, London, 2010. 


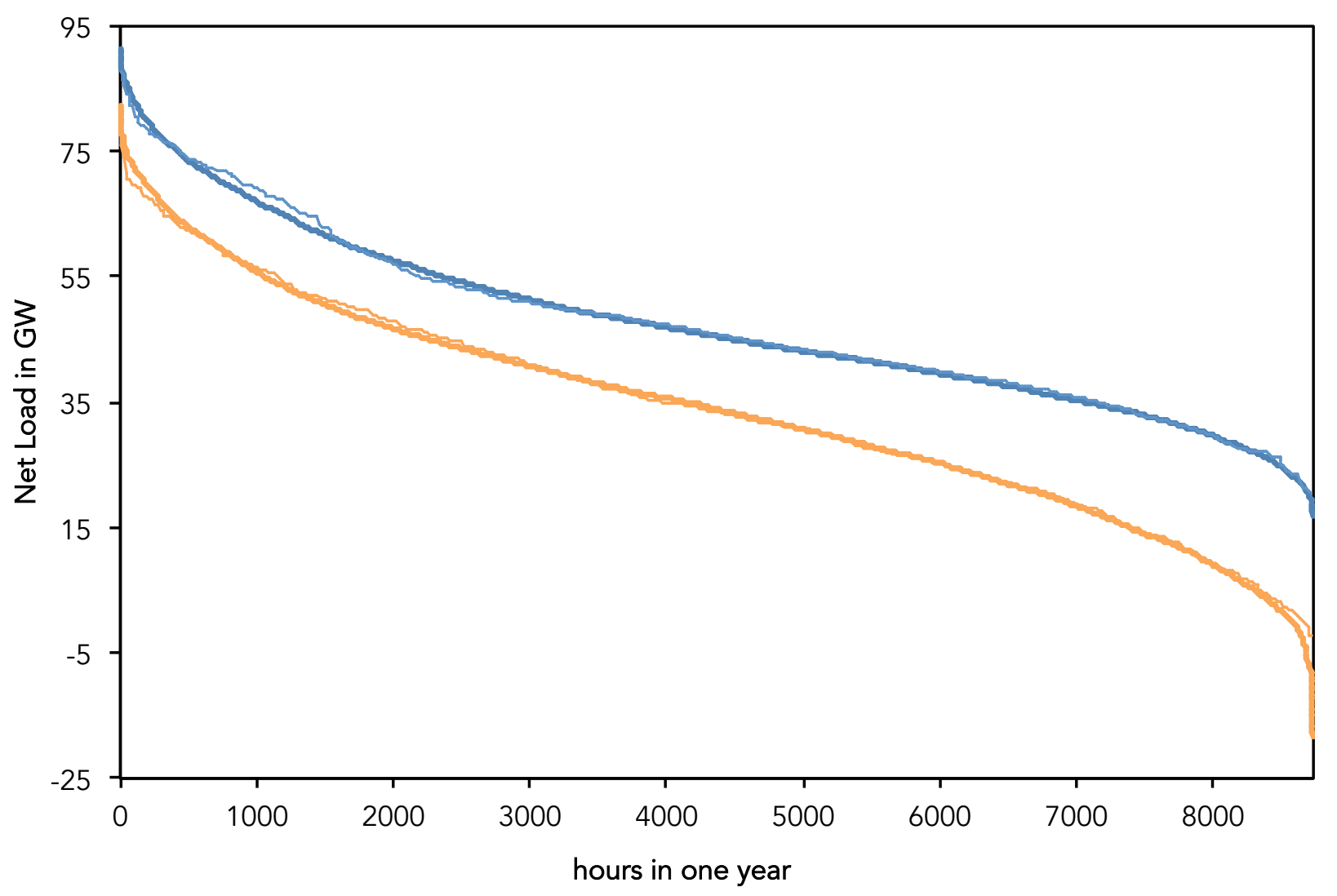

NLDC, unconstrained emissions (6.74 GW solar; $22.81 \mathrm{GW}$ wind)

NLDC, 150 tons/GWh (22.50 GW solar; $50.68 \mathrm{GW}$ wind)

_Four-week approximation, unconstrained emissions

_Four-week approximation, 150 tons/GWh

Fig. 1 


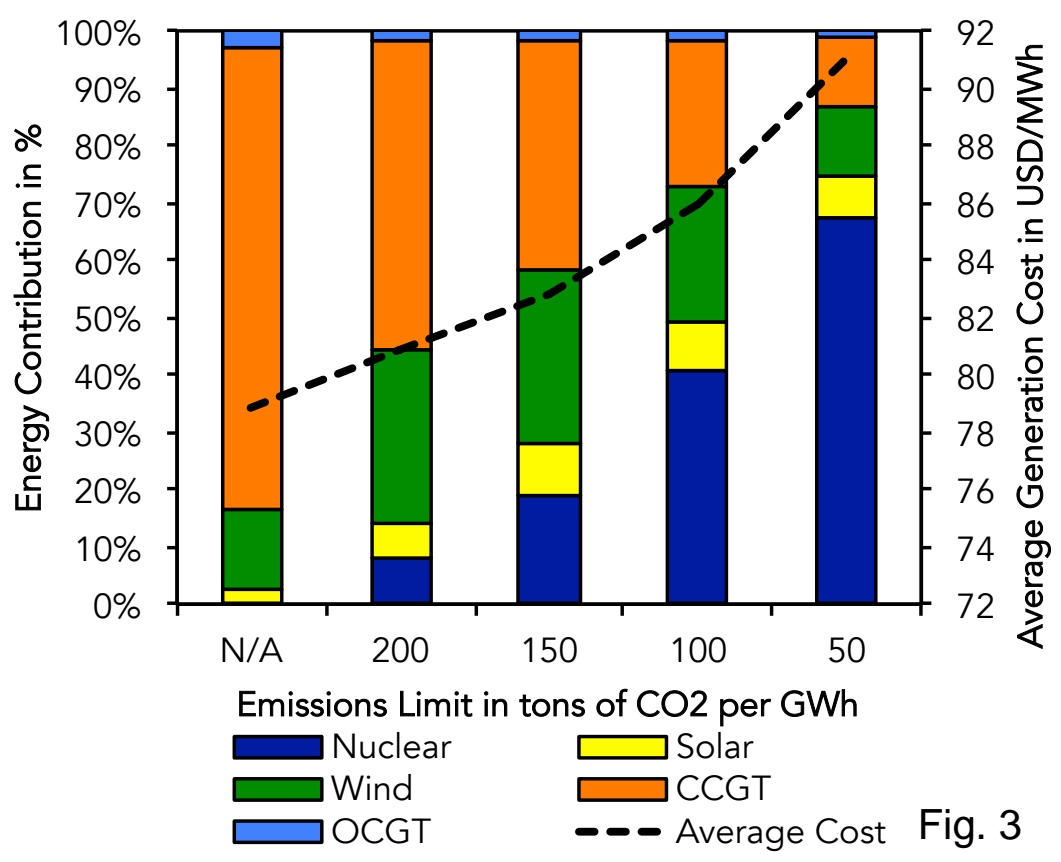




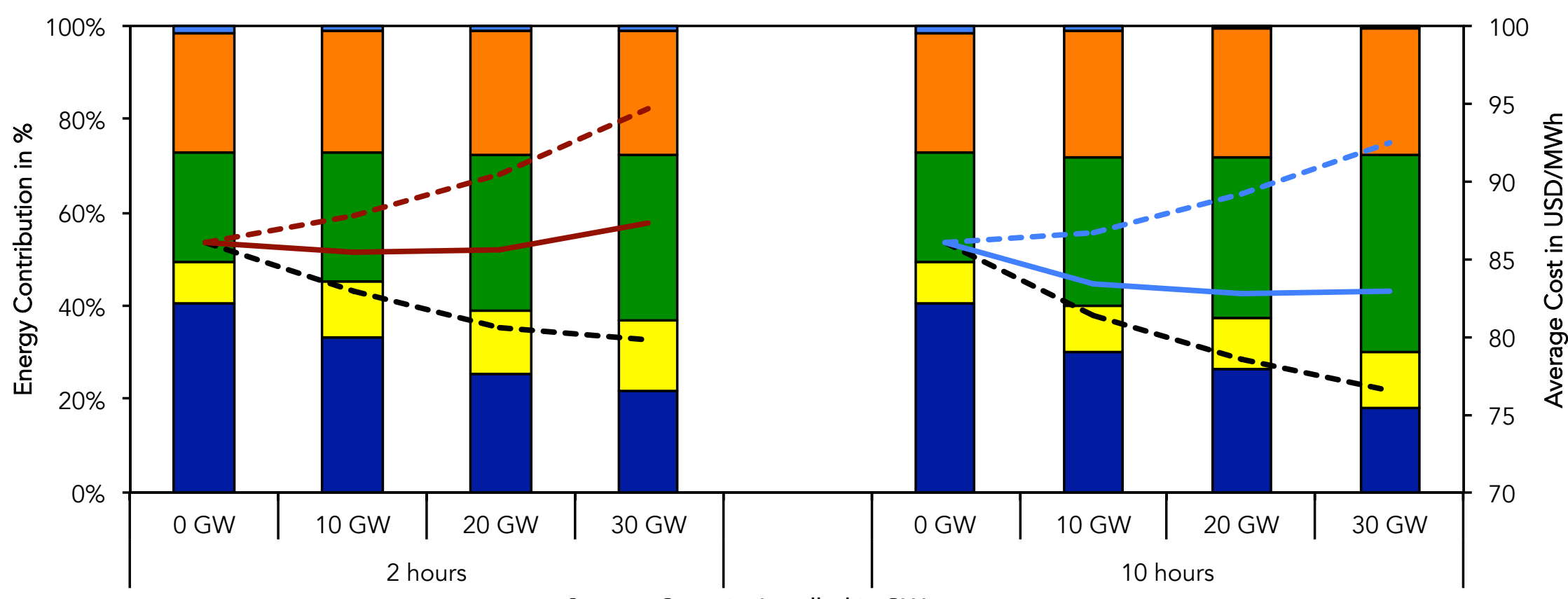

Storage Capacity Installed in GW, per type

\section{OCGT}

Wind

Nuclear

Average System Cost (including current cost Li-ion, 10 year life) Average System Cost (including min. estimated cost of PHS)

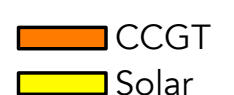

Solar

- Average Generation Cost (excluding storage cost)

Fig. 4

- Average System Cost (including future cost Li-ion, 20 year life)

- Average System Cost (including max. estimated cost of PHS) 


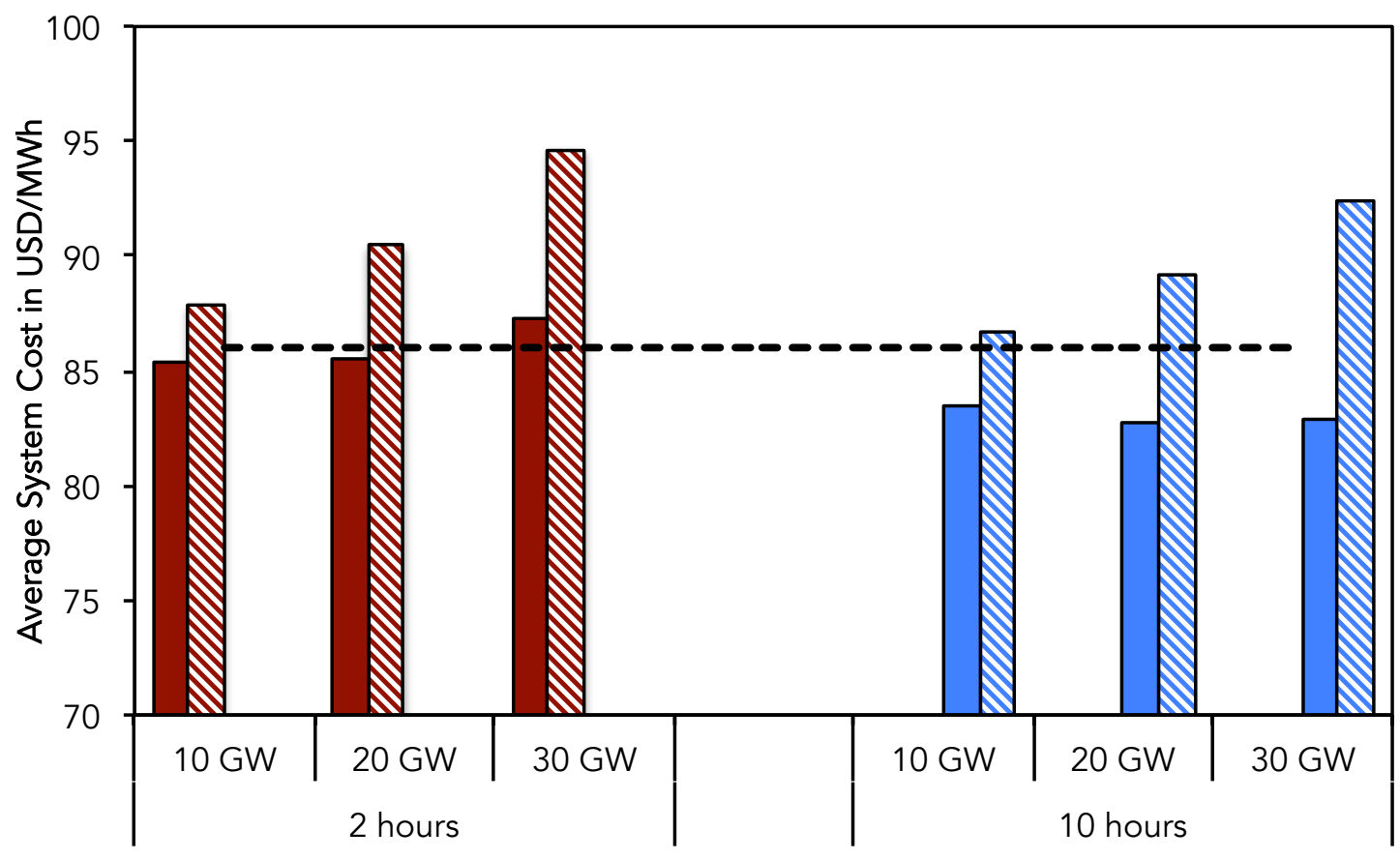

Storage Capacity Installed in GW, per type

$\square$ Average System Cost (including future cost Li-ion, 20 year life) Average System Cost (including current cost Li-ion, 10 year life)

$\square$ Average System Cost (including min. estimated cost of PHS) 110 Average System Cost (including max. estimated cost of PHS) - - Average System cost baseline (no storage) 


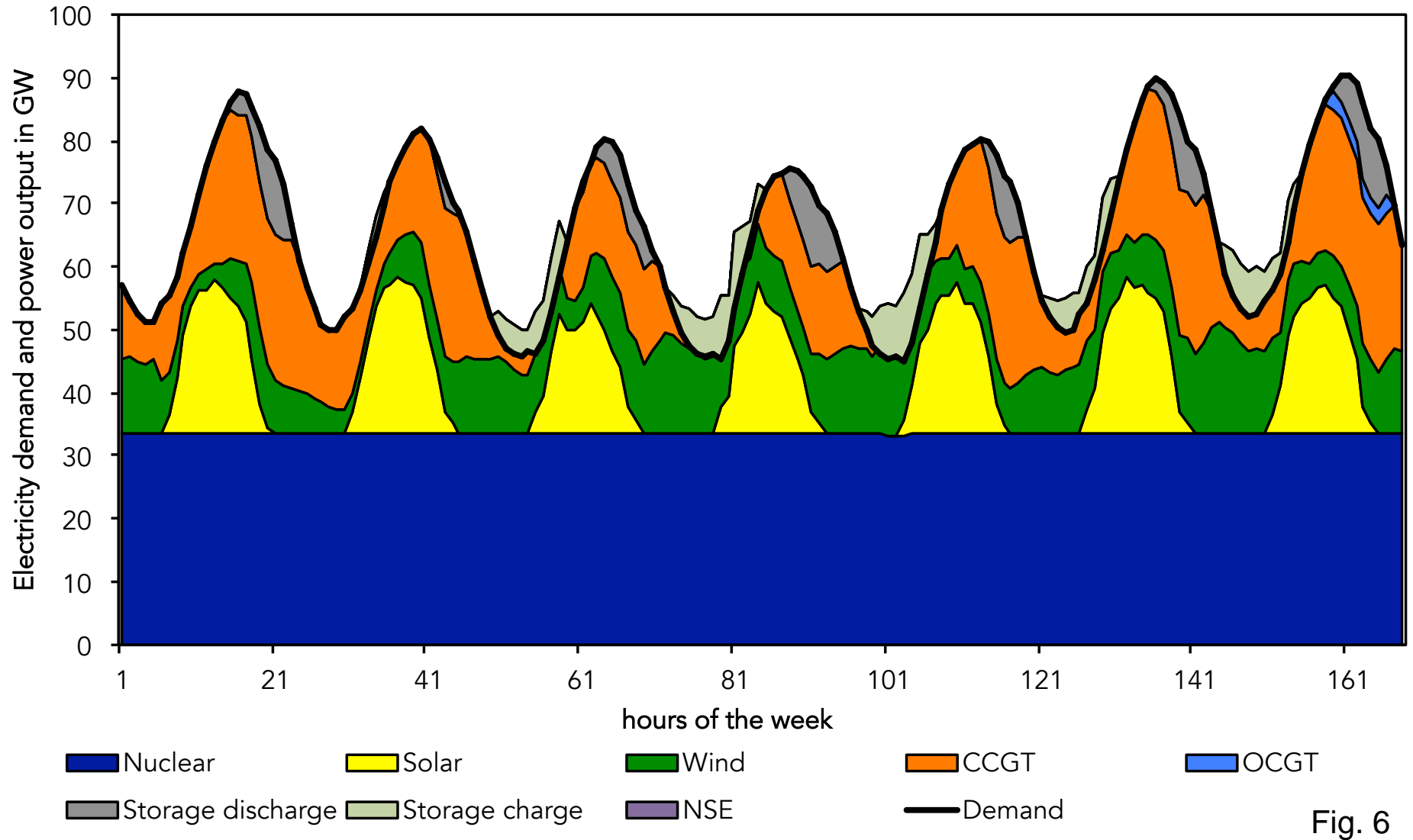




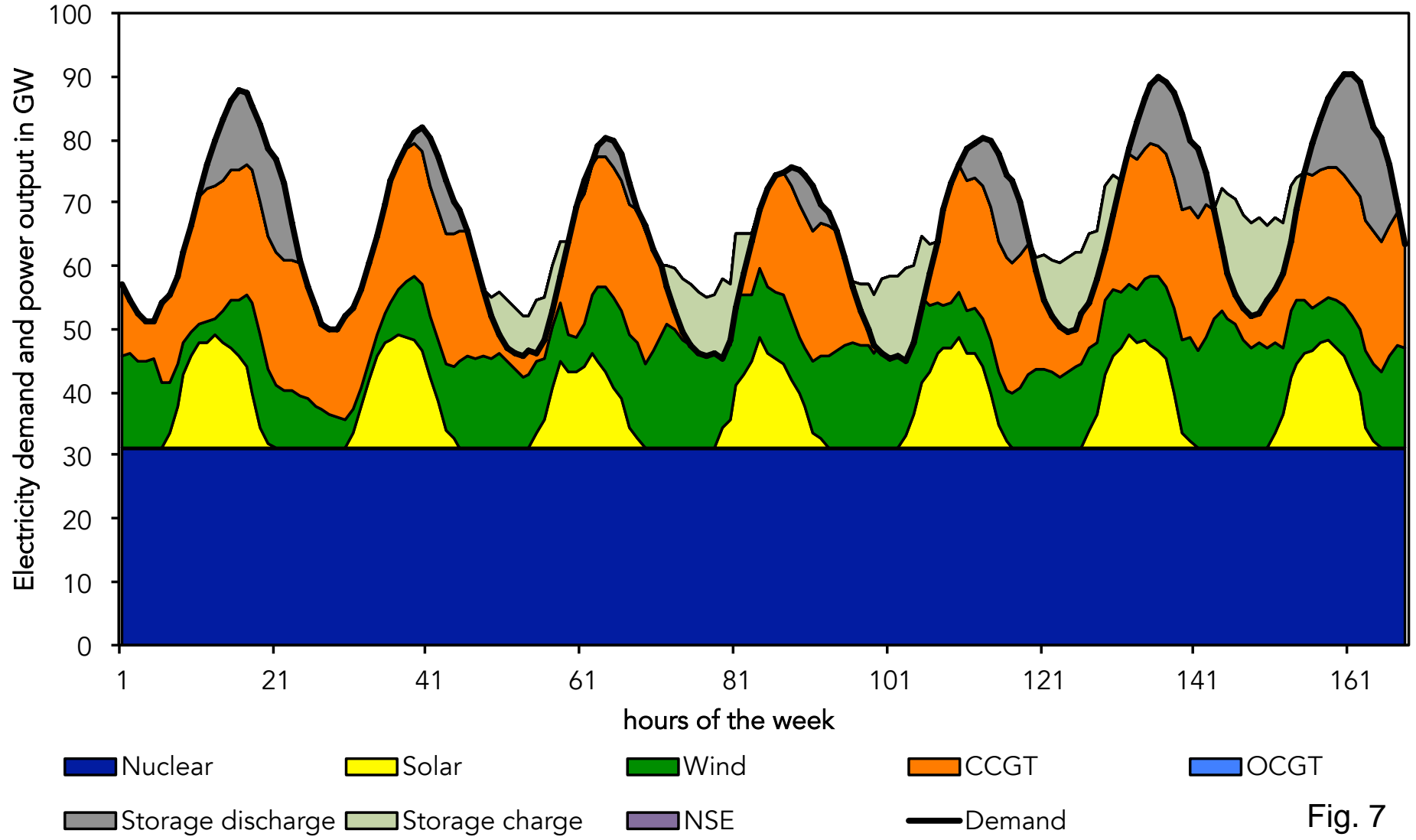




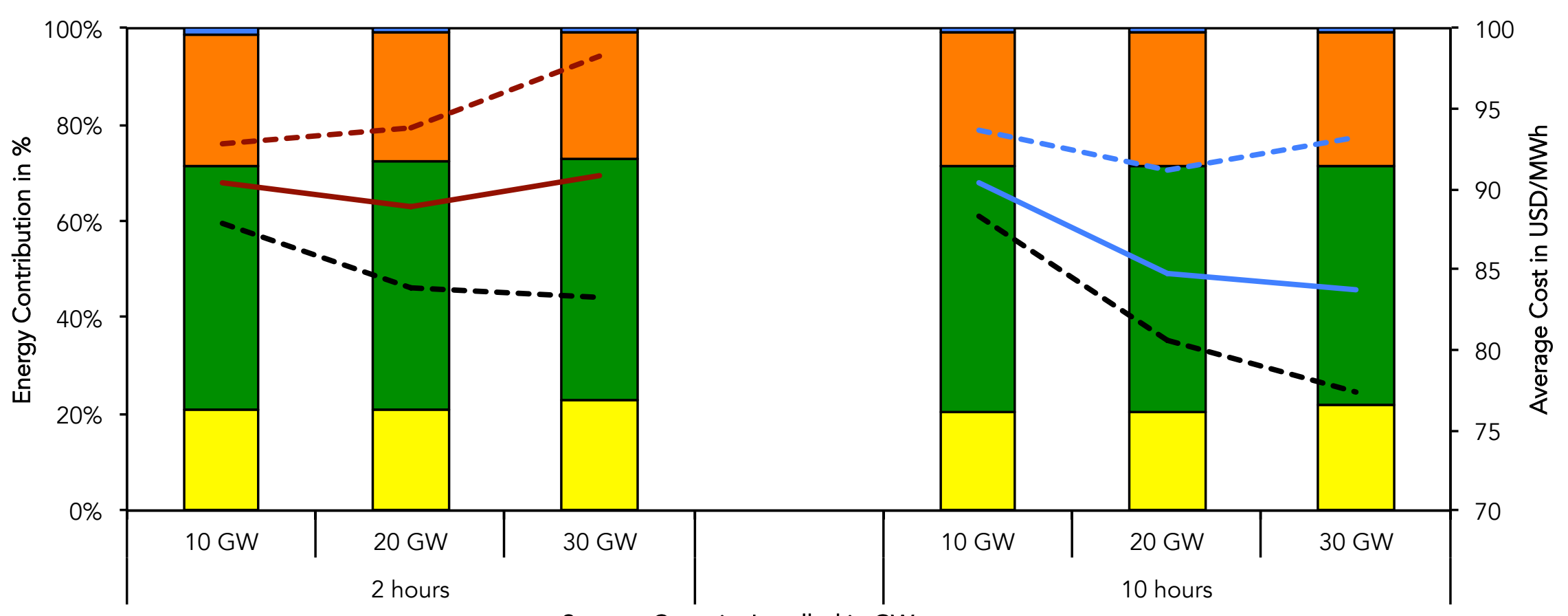

\section{$\square$ OCGT}

Storage Capacity Installed in GW, per type

\section{$\square$ Wind}

- - Average Generation Cost (excluding storage cost)

- - Average System Cost (including current cost Li-ion, 10 year life)

$-\infty$ Average System Cost (including max. estimated cost of PHS)

\section{$\square$ CCGT}

$\square$ Solar

- Average System Cost (including future cost Li-ion, 20 year life) Average System Cost (including min. estimated cost of PHS) 


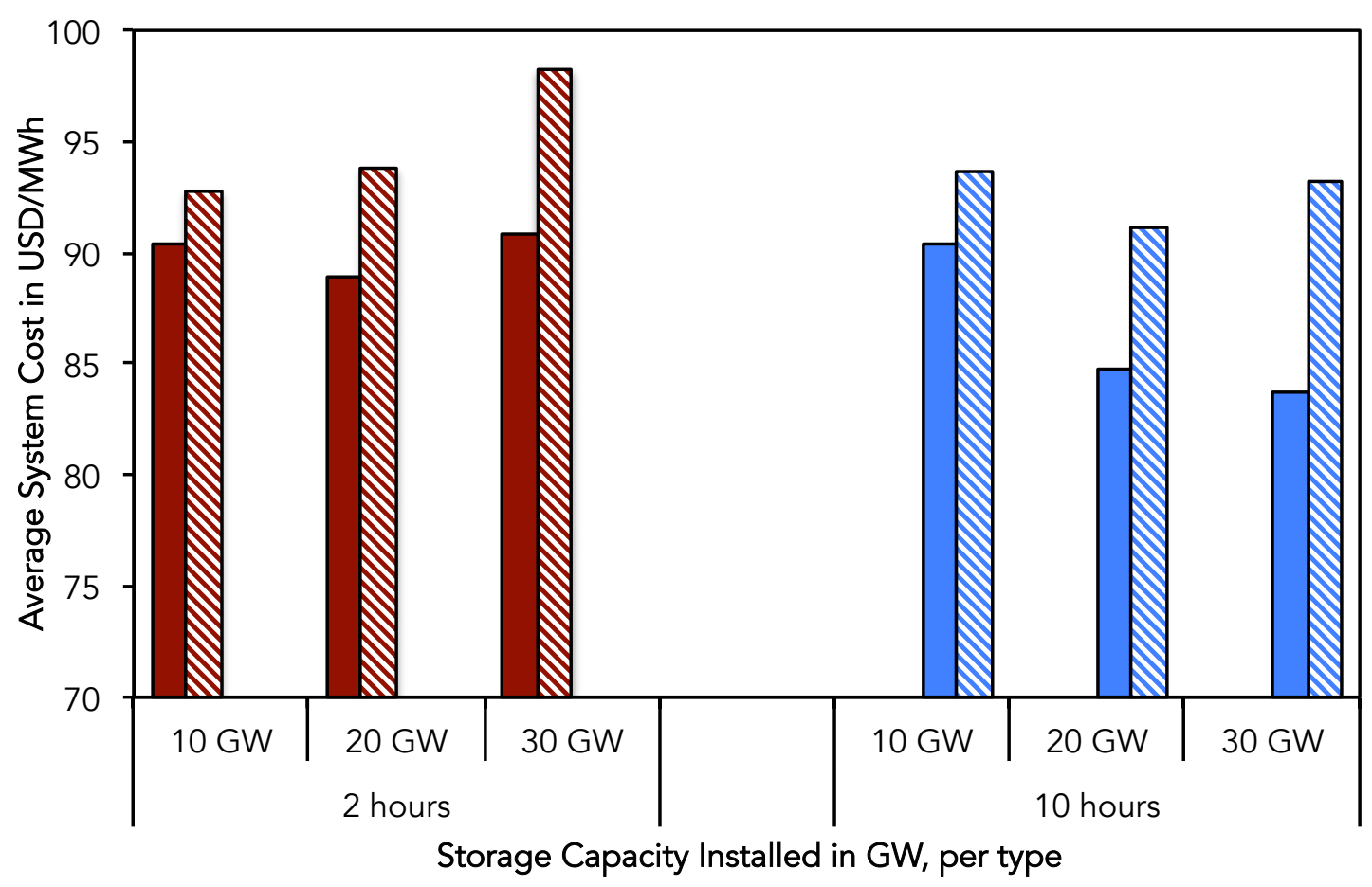

$\square$ Average System Cost (including future cost Li-ion, 20 year life) \$ Average System Cost (including current cost Li-ion, 10 year life) $\square$ Average System Cost (including min. estimated cost of PHS) $\checkmark$ Average System Cost (including max. estimated cost of PHS)

Fig. 9 


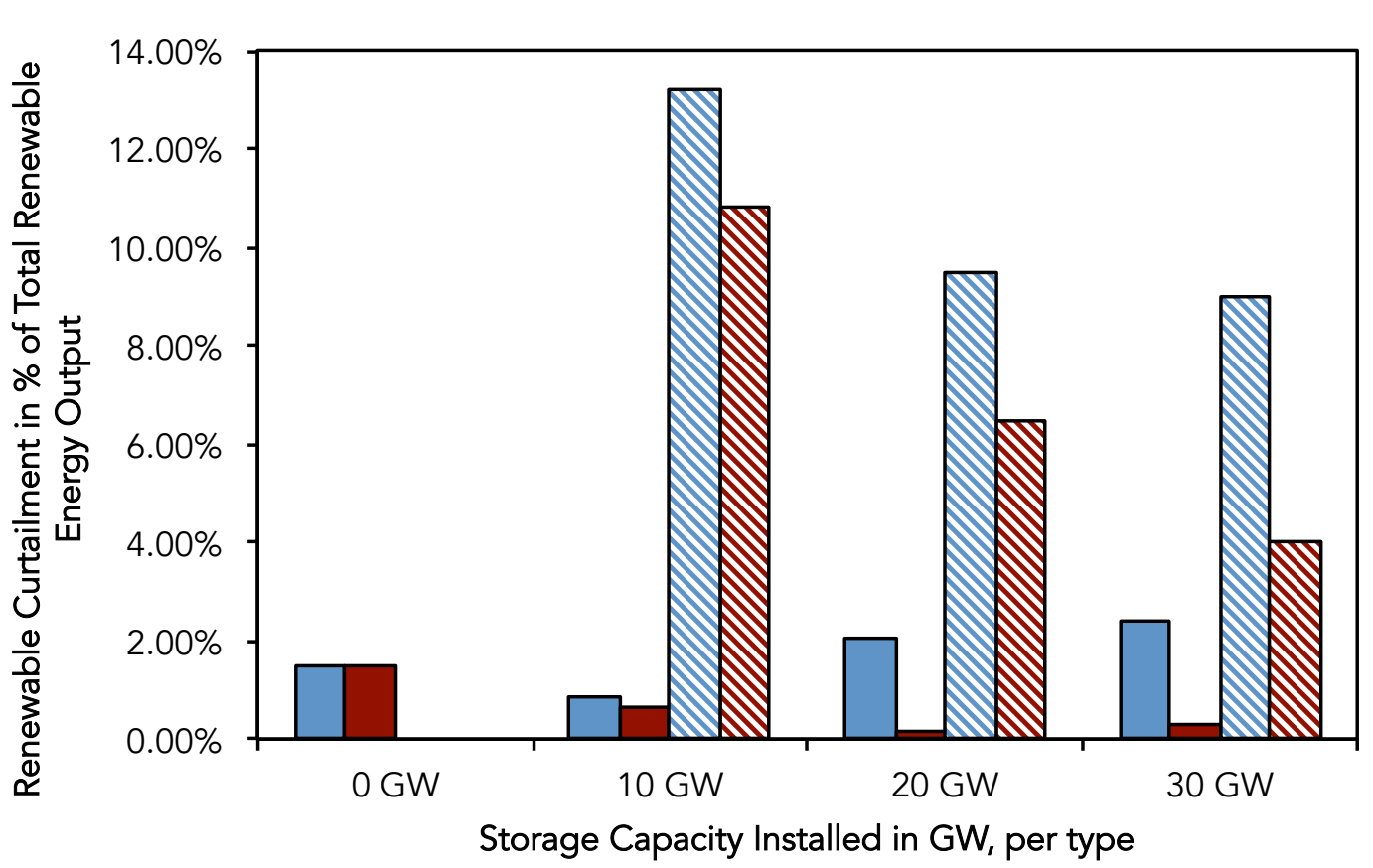

Fig. 10

$\square 2 \mathrm{hr}$ storage

$\nabla 2 \mathrm{hr}$ storage, no nuclear $\square 10 \mathrm{hr}$ storage

$\mathbf{\Delta} 10 \mathrm{hr}$ storage, no nuclear 


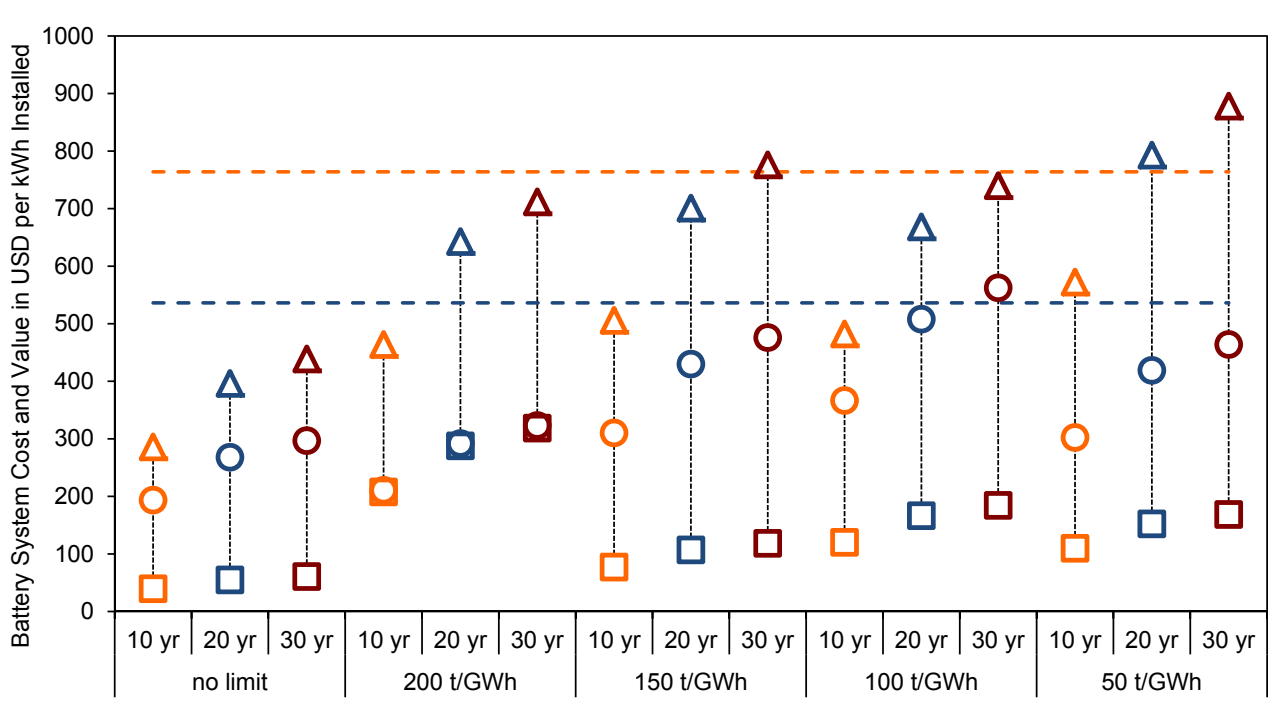

- - - Current estimated cost of Li-ion battery systems ( 10 yr life)

- - - Future potential costs of Li-ion battery systems ( 20 yr life)

$\Delta \quad 0-10 \mathrm{GW}, 10 \mathrm{yr}$ life

- $10-20 \mathrm{GW}, 10 \mathrm{yr}$ life

ㅁ $20-30 \mathrm{GW}, 10 \mathrm{yr}$ life

$\Delta \quad 0-10 \mathrm{GW}, 20 \mathrm{yr}$ life

- $10-20 \mathrm{GW}, 20 \mathrm{yr}$ life

ㅁ $20-30 \mathrm{GW}, 20 \mathrm{yr}$ life

\ $\quad 0-10 \mathrm{GW}, 30 \mathrm{yr}$ life

- $10-20 \mathrm{GW}, 30$ yr life

Fig. 11

$20-30 \mathrm{GW}, 30 \mathrm{yr}$ life 


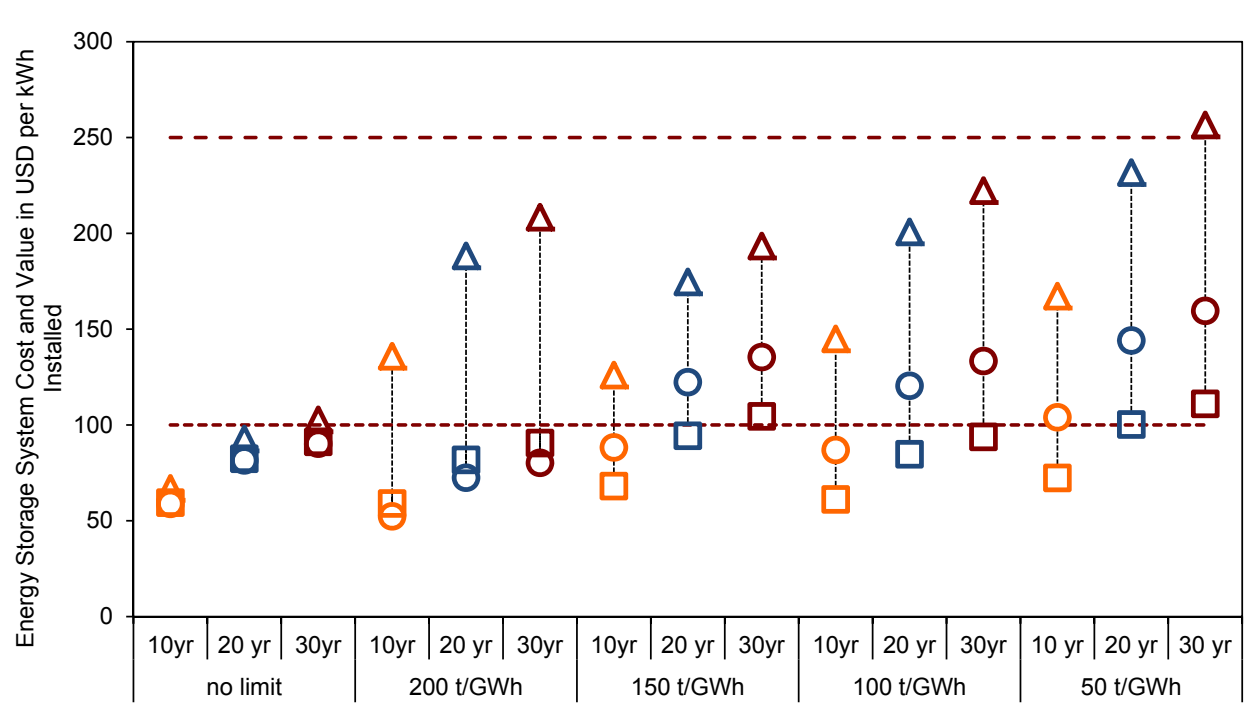

Min. estimated cost of pumped-

hydro storage systems ( 30 yr life)

- - Max. estimated cost of pumpedhydro storage systems ( 30 yr life)

$\Delta \quad 0-10 \mathrm{GW}, 10 \mathrm{yr}$ life

- $10-20 \mathrm{GW}, 10 \mathrm{yr}$ life

ㅁ $20-30 \mathrm{GW}, 10 \mathrm{yr}$ life

$\Delta \quad 0-10 \mathrm{GW}, 20 \mathrm{yr}$ life

- $10-20 \mathrm{GW}, 20$ yr life

$20-30 \mathrm{GW}, 20 \mathrm{yr}$ life

$\Delta \quad 0-10 \mathrm{GW}, 30 \mathrm{yr}$ life

- $10-20 \mathrm{GW}, 30$ yr life

Fig. 12

Emissions Limit in tons of $\mathrm{CO} 2$ per GWh and Expected Life in years

$20-30 \mathrm{GW}, 30 \mathrm{yr}$ life 